\title{
Protection of Inorganic Semiconductors for Sustained, Efficient Photoelectrochemical Water Oxidation
}

\author{
Michael F. Lichterman ${ }^{\mathrm{ab}}$, Ke Sun ${ }^{\mathrm{ab}}$, Shu Hu${ }^{\mathrm{a}, \mathrm{b}, \mathrm{c}}$, Xinghao Zhou ${ }^{\mathrm{b}}$, Matthew T. McDowell ${ }^{\mathrm{a} b}$, \\ Matthew R. Shaner ${ }^{\mathrm{a}, \mathrm{b}}$, Matthias H. Richter ${ }^{\mathrm{b}}$, Ethan J. Crumlin ${ }^{\mathrm{d}}$, Azhar. I. Carim ${ }^{\mathrm{a}}$, Fadl H. Saadi ${ }^{\mathrm{b}}$, \\ Bruce S. Brunschwig ${ }^{c}$, Nathan S. Lewis ${ }^{\text {a,b,c,e }}$ \\ ${ }^{a}$ Division of Chemistry and Chemical Engineering, California Institute of Technology, Pasadena, \\ CA 91125, USA. \\ ${ }^{\mathrm{b}}$ Joint Center for Artificial Photosynthesis, California Institute of Technology, Pasadena, CA \\ 91125, USA. \\ ${ }^{\mathrm{c}}$ Beckman Institute, California Institute of Technology, Pasadena, CA, 91125 USA \\ d Advanced Light Source, Lawrence Berkeley National Laboratory, Berkeley, CA 94720, USA. \\ ${ }^{\mathrm{e}}$ Kavli Nanoscience Institute, California Institute of Technology, Pasadena, CA 91125, USA.
}

\begin{abstract}
Small-band-gap $\left(\mathbf{E}_{\mathrm{g}}<2 \mathrm{eV}\right)$ semiconductors must be stabilized for use in integrated devices that convert solar energy into the bonding energy of a reduced fuel, specifically $\mathrm{H}_{2}(\mathrm{~g})$ or a reduced-carbon species such as $\mathrm{CH}_{3} \mathrm{OH}$ or $\mathrm{CH}_{4}$. To sustainably and scalably complete the fuel cycle, electrons must be liberated through the oxidation of water to $\mathrm{O}_{2}$ (g). Strongly acidic or strongly alkaline electrolytes are needed to enable efficient and intrinsically safe operation of a full solar-driven water-splitting system. However, under water-oxidation conditions, the smallband-gap semiconductors required for efficient cell operation are unstable, either dissolving or forming insulating surface oxides. We describe herein recent progress in the protection of semiconductor photoanodes under such operational conditions. We specifically describe the properties of two protective overlayers, $\mathrm{TiO}_{2} / \mathrm{Ni}$ and $\mathrm{NiO}_{\mathrm{x}}$, both of which have demonstrated the ability to protect otherwise unstable semiconductors for $>100$ h of continuous solar-driven water oxidation when in contact with a highly alkaline aqueous electrolyte (1.0 M KOH(aq)). The
\end{abstract}


stabilization of various semiconductor photoanodes is reviewed in the context of the electronic characteristics and a mechanistic analysis of the $\mathrm{TiO}_{2}$ films, along with a discussion of the optical, catalytic, and electronic nature of $\mathrm{NiO}_{\mathrm{x}}$ films for stabilization of semiconductor photoanodes for water oxidation.

\section{Introduction}

The efficient, sustained oxidation of water is a crucial component of a photoelectrosynthetic solar fuels generator [1, 2]. Cathodic fuel-forming reactions such as the hydrogen-evolution reaction (HER)[3-5] or the carbon-dioxide-reduction reaction $\left(\mathrm{CO}_{2} \mathrm{RR}\right)$ [6] both require the presence of electrons that must come from water oxidation (the oxygenevolution reaction, OER) to ensure sustainability and global scalability. Since the pioneering work by Honda and Fujishima on $\mathrm{TiO}_{2}$ in 1972, easily prepared, inexpensive, and earth-abundant semiconductor materials such as $\mathrm{TiO}_{2}$ have been known to effect stable light-driven water oxidation [7]. Such materials generally have a large band gap $(>3 \mathrm{eV})$ and therefore can contribute significantly to the required voltage needed for sustained water splitting, $1.5-1.7 \mathrm{eV}$, when highly active catalysts of the HER and OER are employed in a minimally resistive cell. Metal oxide photoanodes are however generally limited by either low maximum photocurrent densities and/or instability in relevant media [8-14].

Although only $1.23 \mathrm{~V}$ of potential difference is required to overcome the thermodynamic barrier for the simple process of water splitting, in practice, higher voltages are necessary to overcome solution losses and kinetic barriers to the reactions (equation 1). In equation $1, \eta_{\mathrm{HER}}$ is the overpotential for the HER, $\eta_{\text {OER }}$ is the overpotential for the OER, and iR is the resistance loss through the solution. 


$$
V_{\text {water splitting }}=1.23 \mathrm{~V}+\eta_{\mathrm{HER}}+\eta_{\mathrm{OER}}+i R
$$

Using a single light absorber[15], sustained water splitting is generally limited in the maximum attainable photocurrent density under 1 Sun illumination, because the band gap of the required light absorber is too large to effectively absorb most of the solar spectrum. In contrast, a tandem-device architecture, in which two separate semiconductor materials each provide a substantial contribution towards the needed photovoltage, can produce much higher efficiencies[16-18]. Technologically important semiconductors such as silicon[19], Group IIIV[20], and the Group II-VI [21] semiconductor families, which are generally regarded as 'small band-gap' materials with the appropriate band gaps of 1.1 to $1.7 \mathrm{eV}$ for optimal efficiency [16, 22], provide attractive materials options for the construction of such tandem structures.

However, small-band-gap semiconductors generally corrode under anodic operation, either by active dissolution or by the formation of insulating oxides [23]. The formation of insulating oxides leads to reduced performance or complete non-performance, whereas active corrosion by dissolution catastrophically destroys the semiconductor photoanode. The

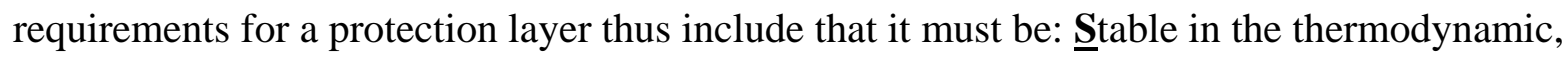
kinetic, and mechanical senses when incorporated onto the semiconductor, immersed in the

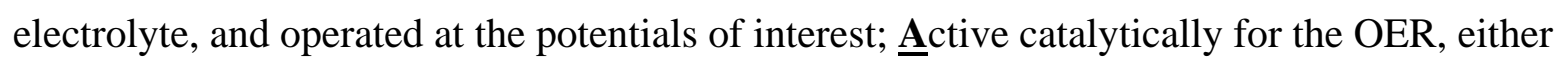
possessing intrinsic catalytic activity or integrating the activity of a co-catalyst; capable of providing Built-in electronic asymmetry to allow for the separation of electrons and holes, or to

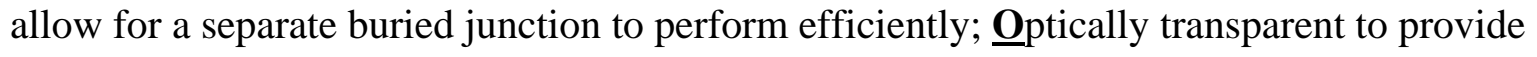
optical properties that are optimized for the transmission of light; and, capable of providing low

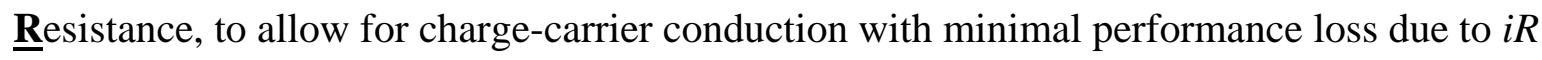
drops. These properties are collectively termed "SABOR". 
Protective coatings have been investigated in detail, but with only secondary emphasis on operation in highly alkaline ( $\mathrm{pH} 14)$ media. Thin metal films have been used for this purpose [24-26], although work has mostly focused on the behavior of photoanodes in buffered media at near-neutral $\mathrm{pH}$. A thin layer of $\mathrm{Ni}$ has been shown to provide substantial stability for $\mathrm{Si}$ photoanodes in alkaline media [26]. $\mathrm{TiO}_{2}$ has been investigated and used as a protective film in alkaline and acidic media, but coatings thicker than a few nm were observed to be highly electrically resistive [27]. Other conventional n-type transparent conductive oxides eventually failed due to corrosion or due to other effects [28] in alkaline media.

We describe herein recent progress in two approaches to enhance the stability of such semiconductor photoanodes while allowing for sustained, efficient water oxidation under conditions where intrinsically safe, efficient solar-driven water-splitting systems can be constructed. In one implementation, $\mathrm{TiO}_{2}$ is used as a protection layer with a sputtered $\mathrm{Ni}$ OER catalyst. We additionally elucidate the applicability of the $\mathrm{TiO}_{2} / \mathrm{Ni}$ layer in terms of morphologies, semiconductors, and electrolytes; the energetics at the semiconductor/ $/ \mathrm{TiO}_{2}$ and the $\mathrm{TiO}_{2} /$ liquid junctions; and mechanisms of charge conduction. For the second implementation, we describe the development of reactively sputtered protective layers of $\mathrm{NiO}_{\mathrm{x}}$ onto various semiconductor surfaces, and also describe the optical, catalytic, and electrical properties of such $\mathrm{NiO}_{\mathrm{x}}$ films.

\section{Previous Work}

Materials such as $\mathrm{SrTiO}_{3}, \mathrm{KTaO}_{3}$, and $\mathrm{TaON}$ are stable as photoanodes for water oxidation, but necessarily have low solar-to-hydrogen efficiencies due to their large band gaps precluding absorption of much of the terrestrial solar spectrum.[29] Generally, a tandem 
structure or triple junction structure is necessary to produce sufficient voltage and current density for efficient water splitting [19, 20, 30]. In addition to use of semiconductor/liquid interfaces as the voltage-generating junction, buried-junction structures, including planar p-n homojunctions[31, 32], semiconductor/metal Schottky barriers[33, 34], spherical[35] and radialjunction microwire[36] electrodes, heterojunctions [37, 38], metal-insulator-semiconductor contacts [9, 15], and emitters derived from in situ inversion layers [21] have all been investigated for use in photoelectrosynthetic or photovoltaic-biased electrosynthetic cells [39]. The efficiencies and main performance characteristics of various reported solar-driven water-splitting systems have been recently compiled [40].

Due to the instability of these small band-gap semiconductors towards photocorrosion, the semiconductors must be kinetically stabilized and/or protected by an overlayer in contact with aqueous electrolytes. The extensive historical efforts to stabilize photoanodes and photocathodes for water splitting, specifically focusing on the development of protection schemes, have been reviewed recently [41]. Some examples include work by Chen, McIntyre and coworkers demonstrating that $\mathrm{TiO}_{2}$ as a tunnel oxide, with a sputtered Ir co-catalyst, can stabilize silicon as a photoanode in acidic, neutral, or basic media[27]. Kenney, Dai and coworkers demonstrated that a thin Ni film allowed for photoelectrochemical water oxidation in both alkaline ( $\mathrm{pH}$ 14) and borate ( $\mathrm{pH}$ 9.5) buffers, although these samples generally exhibited a decrease in stability after $24 \mathrm{~h}$ of operation[26]. An alternate approach by Mei, Chorkendorff, Vesborg and coworkers used thin $\mathrm{Ir} / \mathrm{IrO}_{\mathrm{x}}$ as a protection and catalytic layer for silicon in acidic (1 $\mathrm{M} \mathrm{H}_{2} \mathrm{SO}_{4}$ ) media[42]. Amorphous $\mathrm{Si}: \mathrm{H}$ triple junctions protected by transparent conductive oxides (TCOs), in conjunction with either Pt or with earth-abundant electrocatalysts, have produced solar-to-hydrogen efficiencies of up to 5\%.[43] a-Si:H devices that are protected on 
one side by ZnO in conjunction with a Co-Mo HER catalyst, and protected on the other side by $\mathrm{SnO}_{2}$ in conjunction with an $\mathrm{Fe}-\mathrm{NiO}_{\mathrm{x}}$ OER catalyst, have yielded $\eta_{\mathrm{STH}}=2.5-3.0 \%$ in $1.0 \mathrm{M}$ $\mathrm{KOH}(\mathrm{aq})$, with stability for $>18 \mathrm{~h}$ of operation.[44] Operation in aqueous alkaline electrolytes allows the construction of efficient, intrinsically safe systems and allows use of highly active, low overpotential, earth-abundant electrocatalysts based on $\mathrm{Ni}$ and related alloys.[45] In accord with established properties of commercial electrolyzers, an intrinsically safe electrolysis or photoelectrolysis system does not produce a flammable, potentially explosive mixture of $\mathrm{H}_{2}(\mathrm{~g})$ and $\mathrm{O}_{2}(\mathrm{~g})$ in the reactor at any point in space or time. Common TCO's, such as indium tin oxide (ITO), are not stable in alkaline electrolytes,[30, 46] consequently prior solar-driven watersplitting devices and systems based on a-Si:H triple junctions in $1.0 \mathrm{M} \mathrm{KOH(aq)} \mathrm{failed} \mathrm{due} \mathrm{to} \mathrm{the}$ lack of a stable protective anode coating. In electrolytes buffered in the bulk to near-neutral $\mathrm{pH}$ values, Nocera and coworkers constructed both photoanodes[47] and integrated water-splitting devices[30] by use of a transparent conductive oxide as a conductive contact between the PV cell and Co-based electrocatalysts[48]. Electrolysis or photoelectrolysis systems that are operated in buffered or unbuffered bulk near-neutral $\mathrm{pH}$ electrolytes are inefficient and/or not intrinsically safe. $[17,48-50]$

\section{3. $\mathrm{TiO}_{2}$}

\subsection{Background}

$\mathrm{TiO}_{2}$ was investigated as a photoanode for water splitting [7] before being used in dyesensitized solar cells[51]. $\mathrm{TiO}_{2}$ has also been used as a gate dielectric [52], with different deposition conditions producing markedly different conductivities and materials properties. $\mathrm{TiO}_{2}$ has been used as a protection layer, but films thicker than a few nm were highly resistive [27]. 


\subsection{Planar Materials and ALD-TiO}

$\mathrm{TiO}_{2}$ deposited using atomic-layer deposition (ALD) at $150{ }^{\circ} \mathrm{C}$ from tetrakis dimethylamido titanium (TDMAT) is highly resistive as-deposited. Unless indicated otherwise, “ALD-TiO 2 " generally refers to films produced in this manner from this precursor. These films became very conductive towards anodic current flow following the sputter-deposition of a $\mathrm{Ni}$ film or Ni islands[22]. As a result, over $100 \mathrm{~nm}$ of $\mathrm{ALD}-\mathrm{TiO}_{2}$ could be deposited onto a semiconductor without concern for resistive losses in the film.

Further experiments were undertaken with $\mathrm{TiO}_{2}$ deposited in a variety of ways from various precursors. After such films were deposited, buried-junction n-p ${ }^{+}$Si photoanodes operated continuously for water oxidation for up to $100 \mathrm{~h}$ in $1.0 \mathrm{M} \mathrm{KOH}(\mathrm{pH}=14)$. ALD-TiO 2 with Ni also formed an efficient photoanode when placed directly on n-Si, forming a highperformance silicon/metal-oxide heterojunction. Specifically, photovoltages of up to $410 \mathrm{mV}$ and photocurrent densities of up to $28 \mathrm{~mA} \mathrm{~cm}^{-2}$ were observed on n-Si/ALD-TiO $/ \mathrm{Ni}$ photoanodes in contact with 1.0 M KOH(aq) under 1 sun Air Mass (AM) 1.5G illumination. Under identical conditions, n- $\mathrm{p}^{+} \mathrm{GaAs} / \mathrm{ALD}-\mathrm{TiO}_{2} / \mathrm{Ni}$ photoanodes provided photovoltages of $810 \mathrm{mV}$ and photocurrent densities of up to $14.3 \mathrm{~mA} \mathrm{~cm}{ }^{-2}$. Additionally, $\mathrm{n}-\mathrm{GaP} / \mathrm{ALD}-\mathrm{TiO}_{2} / \mathrm{Ni}$ photoanodes provided photovoltages of $590 \mathrm{mV}$ and photocurrent densities of $3.4 \mathrm{~mA} \mathrm{~cm}^{-2}$, and n-CdTe/ALD-TiO $2 / \mathrm{Ni}$ photoanodes [53] produced $435 \mathrm{mV}$ of photovoltage and $21 \mathrm{~mA} \mathrm{~cm}^{-2}$ of photocurrent density. Figure 1a shows representative current density vs potential $(J-E)$ data for such n-Si, np ${ }^{+}-\mathrm{Si}, \mathrm{np}^{+}-\mathrm{GaAs}$, and n-CdTe photoanodes with $\mathrm{ALD}-\mathrm{TiO}_{2} / \mathrm{Ni}$ coatings and in contact with $1.0 \mathrm{M} \mathrm{KOH}(\mathrm{aq})$. Figure $1 \mathrm{~b}$ shows the current density vs time behavior of a representative n-Si/ALD- $\mathrm{TiO}_{2} / \mathrm{Ni}$ photoanode. The low temperature used for the deposition, and the conformal nature of the ALD process, are beneficial for the deposition of $\mathrm{TiO}_{2}$ onto 
otherwise easily oxidized materials, where a thick surface oxide can lead to substantially decreased performance and where pinholes can lead to destruction of the device. Figure 1c shows an image from a transmission-electron microscopy (TEM) investigation of the structure of the $\mathrm{Si} / \mathrm{ALD}-\mathrm{TiO}_{2}$ junction, indicating that an $\sim 1 \mathrm{~nm}$ thick mixed $\mathrm{Si} / \mathrm{Ti}$ oxide formed at the interface between the Si and the $\mathrm{TiO}_{2}$.
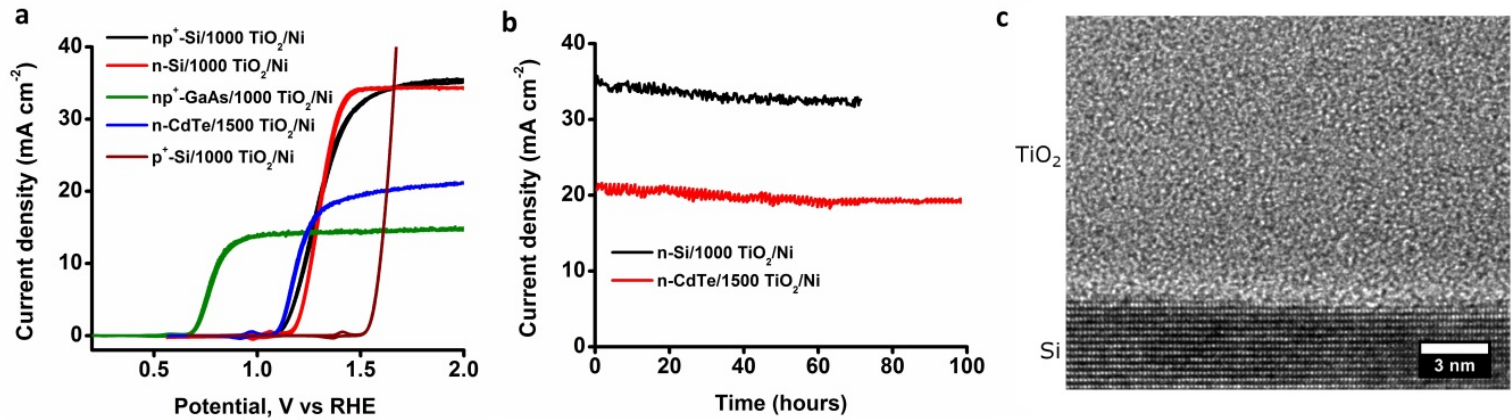

Figure 1. (a) $J-E$ data for representative photoelectrodes in contact with $1.0 \mathrm{M} \mathrm{KOH(aq).}$

Conditions for the n-p ${ }^{+}$-Si and n-Si photoanodes were 1.25 suns of AM 1.5G illumination, whreas the data for n-CdTe and $\mathrm{np}^{+}$GaAs photoanodes were obtained under 1 sun of AM 1.5G illumination. (b) Current density vs time for an n-Si/ALD-TiO $2 / \mathrm{Ni}$ photoanode immersed in 1.0 $\mathrm{M} \mathrm{KOH}(\mathrm{aq})$ at a potential of $2 \mathrm{~V}$ vs. RHE, and for an n-CdTe/ALD-TiO $/ 2 \mathrm{Ni}$ photoanode held at 2.07 V vs. RHE. (c) A transmission-electron microscopy (TEM) image of the $\mathrm{Si}^{-\mathrm{ALD}-\mathrm{TiO}_{2}}$ interface, showing the thin oxide layer (brighter layer between the $\mathrm{TiO}_{2}$ and the $\mathrm{Si}$ ). Data reproduced from references [22, 53, 54].

\subsection{Wire Geometries}


The above systems all demonstrated the ability of the ALD- $\mathrm{TiO}_{2} / \mathrm{Ni}$ combination to protect planar semiconductors in alkaline media. Buried-junction Si microwires with radial emitter layers, grown by a vapor-liquid-solid (VLS) process, have been used as photocathodes[35] as well as photoanodes[37]. $\mathrm{np}^{+}$-Si microwires, coated with $\mathrm{ALD}-\mathrm{TiO}_{2}$ and then with sputter-deposited a $\mathrm{NiCrO}_{\mathrm{x}}$ catalyst, operated for $>2000 \mathrm{~h}$ of continuous light-driven photoelectrochemical water oxidation in contact with $\mathrm{pH}=14 \mathrm{KOH}(\mathrm{aq})$ [55]. The microwire arrays produced $440 \mathrm{mV}$ and $7.1 \mathrm{~mA} \mathrm{~cm}^{-2}$ of photovoltage and photocurrent density, respectively, at 1 sun illumination while containing only $4 \%$ of the material present in a silicon wafer of the same area. The titania overlayer also protected n-Si microwires, but produced substantially less photovoltage (200 $\mathrm{mV}$ at 1 sun) than was obtained from the $\mathrm{np}^{+}-$ $\mathrm{Si} / \mathrm{TiO}_{2} / \mathrm{NiCrO}_{\mathrm{x}}$ microwire array photoanode. Figure 2 shows $\mathrm{SEM}$ images of the $\mathrm{Si} / \mathrm{ALD}-\mathrm{TiO}_{2}$ microwire arrays (2a) as well as a cross-sectional image of a single $\mathrm{Si} / \mathrm{ALD}-\mathrm{TiO}_{2}$ microwire on a device (2b). Figure 2c shows the $J$ - $E$ behavior of the material, whereas Figure 2d depicts the current density vs time for representative microwire array photoanodes. The observed stability is likely a result of the confluence of two primary factors: the low effective current density at the surface of a microwire, due to the high surface area of the microwire array, and the isolation of failure points to single microwires rather than the propagation of failures throughout the device. 

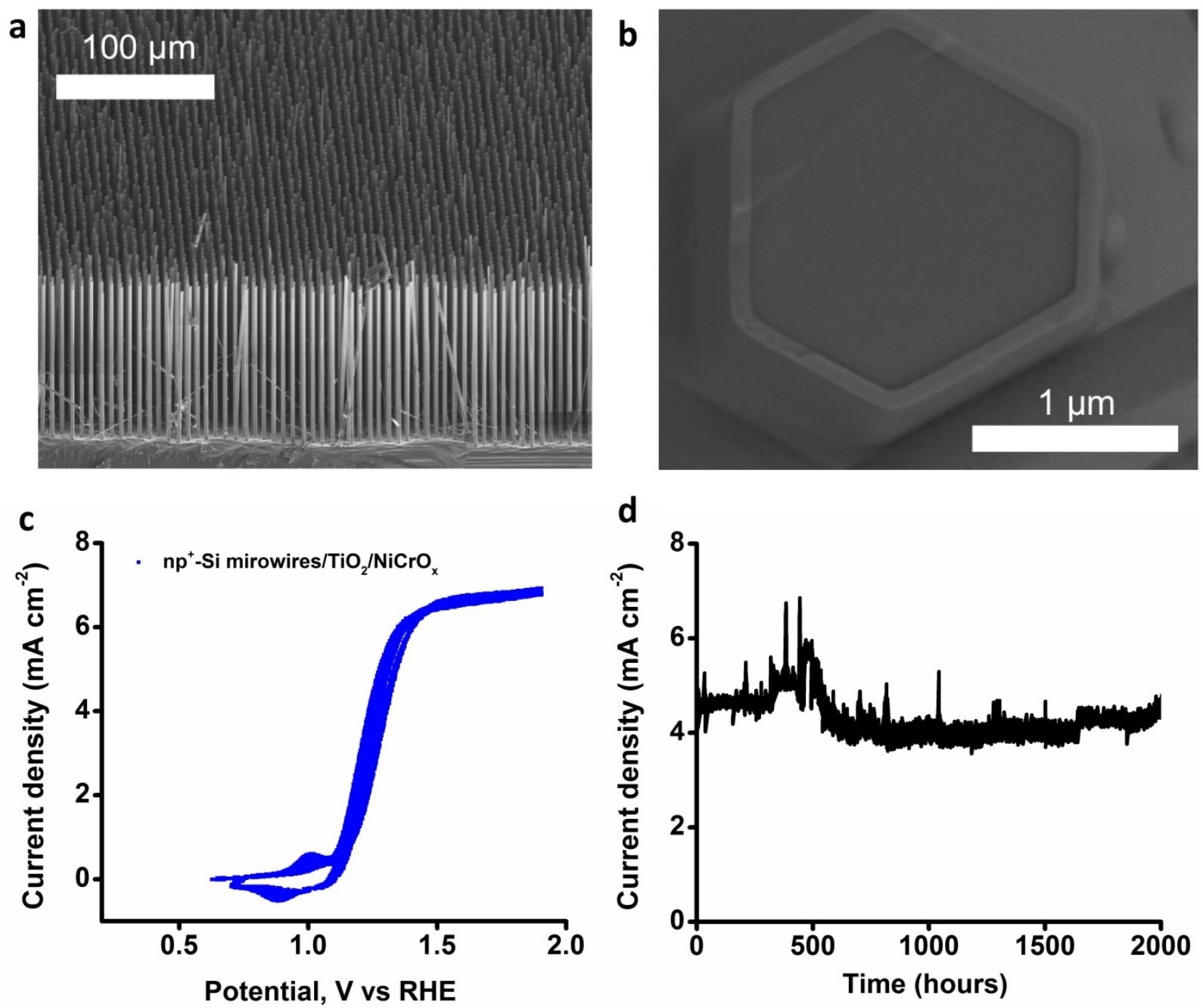

Figure 2. (a) Scanning-electron microscope (SEM) image of a Si microwire array and (b) a cross-sectional image of a single $\mathrm{Si} / \mathrm{ALD}-\mathrm{TiO}_{2}$ microwire. (c) Current-density vs potential (J-E) data for an $\mathrm{np}^{+}$-Si/ALD-TiO $2 / \mathrm{NiCrO}_{\mathrm{x}}$ microwire array under 1 sun illumination and in contact with 1.0 M KOH(aq). (d) Current density vs time for the same device as in (c) held a potential of $1.59 \mathrm{~V}$ vs. RHE while in contact with $1.0 \mathrm{M} \mathrm{KOH}(\mathrm{aq})$ and under simulated solar illumination. Data reproduced from reference [55].

3.4 $\mathrm{TiO}_{2}$ Films - Different Processing Methods and Crystal Structures 
$\mathrm{n}-\mathrm{Si} / \mathrm{TiO}_{2} / \mathrm{Ni}$ photoandoes have also been fabricated using titania that has been deposited using a variety of methods, or otherwise annealed (at moderate temperatures, $\sim 400-500^{\circ} \mathrm{C}$ ) postdeposition[54]. The TDMAT-ALD films annealed at these moderate temperatures in air and forming gas, as well as films deposited by sputtering and with ALD using a titanium tetraisopropoxide (TTIP) precursor, also acted as rectifying and conductive contacts to n-Si (Figure 3a). X-ray photoelectron spectroscopy (XPS), Raman spectroscopy, and TEM were used to elucidate the structural and chemical properties of these various titania layers. XPS demonstrated that the as-deposited ALD-TDMAT- $\mathrm{TiO}_{2}$ contained a substantial number of midgap defect states, whereas sputtered $\mathrm{TiO}_{2}$ as well as $\mathrm{TiO}_{2}$ prepared by other ALD methods showed a lesser number of such states near $1 \mathrm{eV}$ binding energy (Figure 3b). The ALDTDMAT- $\mathrm{TiO}_{2}$ was amorphous[22], whereas sputter-deposited $\mathrm{TiO}_{2}$ was a mixture of anatase and rutile (Figure 3c and 3f), and ALD-TTIP-TiO ${ }_{2}$ films were anatase (Figure 3g). Nevertheless, all of the films deposited conformally on planar substrates, had similar Ti 2p core level XPS characteristics (Figure 3d), and showed a large ( 10 micron) grain size by cross-sectional TEM (Figure 3e), suggesting that the conduction was predominantly through the $\mathrm{TiO}_{2}$ and was not due to conduction through a secondary phase or through grain boundaries. Although the films were conductive, the lower performance of the resulting devices, and the highly surface-sensitive nature of XPS, suggests that the defect states and energetics present in the ALD-TDMAT-TiO ${ }_{2}$ may play an important role in the operational characteristics of these devices. 

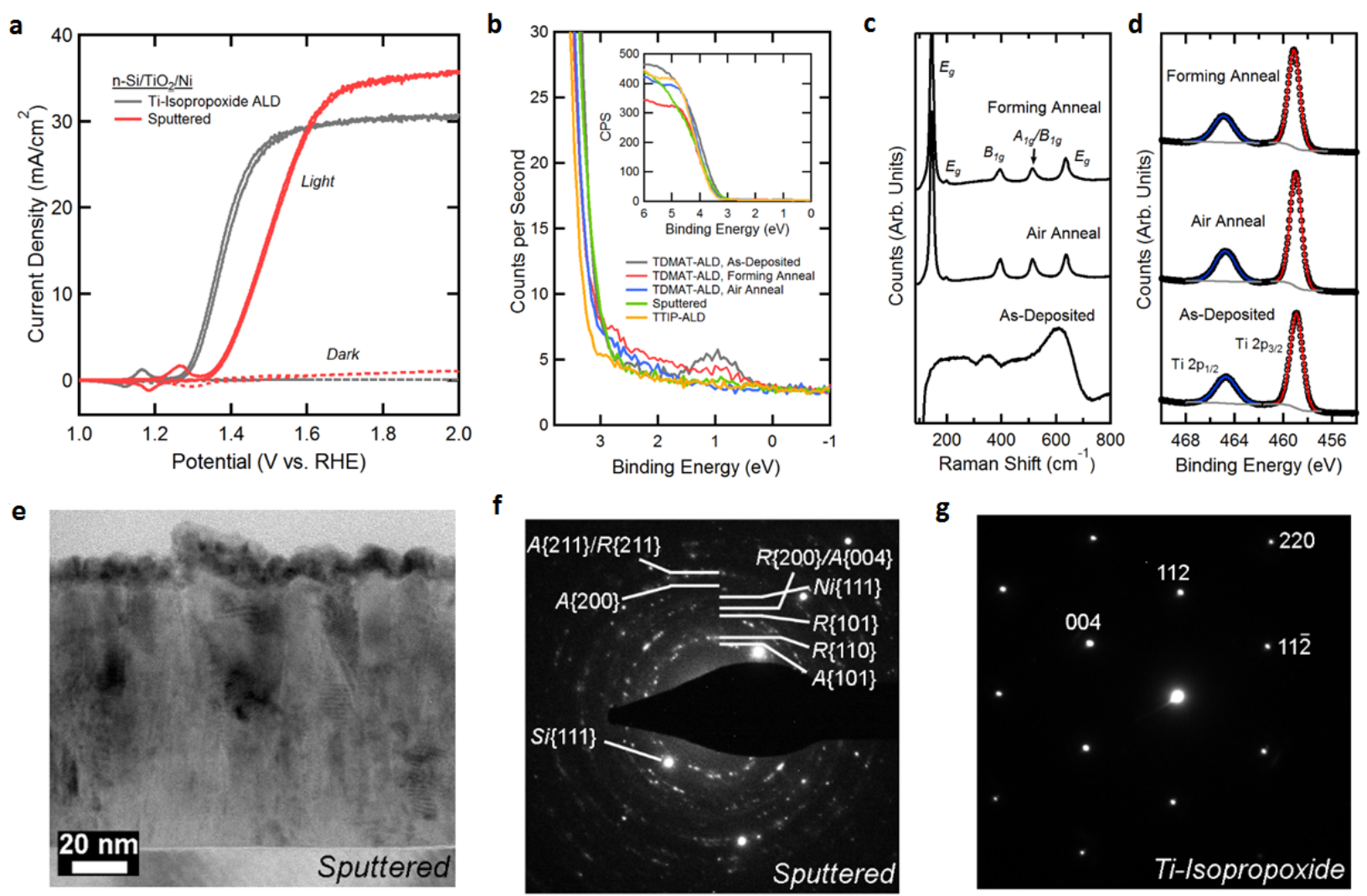

Figure 3. (a) Current-density vs potential (J-E) data in the dark and under 1 sun illumination, respectively, for n-Si/ALD-TTIP- $\mathrm{TiO}_{2} / \mathrm{Ni}$ and $\mathrm{n}$-Si/sputtered- $\mathrm{TiO}_{2} / \mathrm{Ni}$ photoanodes in contact with $1.0 \mathrm{M} \mathrm{KOH} \mathrm{(aq).} \mathrm{(b)} \mathrm{XPS} \mathrm{data} \mathrm{of} \mathrm{the} \mathrm{valence-band} \mathrm{region} \mathrm{for} \mathrm{ALD-TDMAT} \mathrm{TiO} 2$; ALDTDMAT $\mathrm{TiO}_{2}$ annealed in either forming gas or air; TTIP-ALD- $\mathrm{TiO}_{2}$; and sputtered $\mathrm{TiO}_{2}$ films, respectively. Defect states were most evident in the as-deposited TDMAT-ALD-TiO 2 . (c) and (d): Raman and XPS investigation of the as-deposited and annealed TDMAT-ALD- $\mathrm{TiO}_{2}$ layers, in which Raman shifts indicative of anatase are evident in the annealed samples although no substantial differences were observed in the titanium 2p XPS core level signals. (e) Crosssectional transmission-electron microscope (TEM) image of Si/sputtered- $\mathrm{TiO}_{2}$. (f) and (g): Diffraction patterns from selected-area electron diffraction (SAED) indicating both anatase and rutile crystalline structures in the sputtered $\mathrm{TiO}_{2}$ film, but only anatase in the TTIP-ALD-TiO film. Data reproduced from reference [54]. 


\subsection{Systems Analysis}

The energetics of the $\mathrm{TiO}_{2}$-stabilized photoanodes have been investigated using three distinct approaches: the construction and analysis of a solid-state n-Si/ALD- $\mathrm{TiO}_{2} / \mathrm{Ni}$ photovoltaic; investigation by operando XPS of the ALD-TiO $/$ /liquid and ALD-TiO $/ \mathrm{Ni} /$ liquid junctions; and investigation by solid-state approaches of various $\mathrm{TiO}_{2} /$ metal junctions.

Photovoltaic devices consisting of $\mathrm{n}-\mathrm{Si} / \mathrm{ALD}-\mathrm{TiO}_{2} / \mathrm{Ni}$ were constructed in which the $\mathrm{Ni}$ was sputtered into bus-bars using photolithographic patterning. Such devices, when the ALD$\mathrm{TiO}_{2}$ was sufficiently thick (68 nm), provided $390 \pm 20 \mathrm{mV}$ of open-circuit photovoltage, along with a short-circuit photocurrent density of $9.3 \pm 1.4 \mathrm{~mA} \mathrm{~cm}^{-2}$ and a fill factor of 0.42 . Similar results were observed when $\mathrm{n}-\mathrm{Si} / \mathrm{ALD}-\mathrm{TiO}_{2} / \mathrm{Ni}$ photoanodes were placed in contact with nonaqueous, one-electron, electrochemically reversible redox couples. Importantly, beyond a few $\mathrm{nm}$, the photovoltages of n-Si/ALD- $\mathrm{TiO}_{2}$ electrodes were effectively constant as the thickness of the $\mathrm{TiO}_{2}$ increased.

XPS was used to investigate the energetics of the n-Si/ALD- $\mathrm{TiO}_{2}$ junction for thicknesses of titania ranging from 0 to 1000 ALD cycles ( 0 to $\sim 45 \mathrm{~nm}$ ). The oxide peak in the silicon $2 \mathrm{p}$ region suggested the presence of a mixed interfacial oxide of $\mathrm{Si}_{\mathrm{x}} \mathrm{Ti}_{\mathrm{y}} \mathrm{O}_{2}$. Furthermore, the electronic shifts observed in the $\mathrm{TiO}_{2}$ and underlying $\mathrm{Si}^{0}$ layer were nearly identical beyond the first $\sim 10 \mathrm{ALD}$ cycles of $\mathrm{TiO}_{2}$ deposition, suggesting that although the initial few ALD cycles produce a mixed oxide, the photovoltage for the following cycles originated predominantly from the $\mathrm{n}$-Si space-charge region; i.e, for the $\mathrm{n}-\mathrm{Si} / \mathrm{TiO}_{2}$ interface, the band bending primarily was present in the n-Si as opposed to in the $\mathrm{TiO}_{2}$. For thick ALD-TiO layers, XPS indicated the presence of a defect band at $\sim 1 \mathrm{eV}$ in binding energy within the $\mathrm{TiO}_{2}$ band gap. 
The energetics present at the n-Si/ALD- $\mathrm{TiO}_{2}$ junction were also analyzed by solid-state transport behavior in the absence of illumination. The dark $J$-E behavior was fitted to the diode equation:

$$
J=A^{*} T^{2} \exp \left(-\frac{q \emptyset_{B}}{k T}\right)\left[\exp \left(\frac{q V}{n k T}\right)-1\right]=J_{0}\left[\exp \left(\frac{q V}{n k T}\right)-1\right]
$$

where $A *$ is the effective Richardson constant, $T$ is the absolute temperature, $\emptyset_{B}$ is the barrier height of the rectifying junction, $J_{0}$ is the dark saturation current density, and $n$ is the diode quality factor. Values for $J_{0}$ and $n$ were obtained from extrapolations of the linear regions of the dark $J$-E data plotted in a log-linear fashion. These results indicated that the effective Richardson constant for these devices was $\sim 1.87 \mathrm{~A} \cdot \mathrm{cm}^{-2} \cdot \mathrm{K}^{-2}$, which is approximately two orders of magnitude smaller than typical values of $120 \mathrm{~A} \cdot \mathrm{cm}^{-2} \cdot \mathrm{K}^{-2}$ for $\mathrm{n}-\mathrm{Si} / \mathrm{metal}$ Schottky barriers[56].

Further XPS experiments were performed to elucidate in detail the $\mathrm{TiO}_{2} /$ solution interface with and without the presence of Ni. Specifically, operando XPS was performed on beamline 9.3.1 at the Advanced Light Source. The end-station on this beamline allowed for the collection of XPS data through a thin ( $13 \mathrm{~nm}$ thick) electrolyte meniscus in conjunction with collecting photoelectrons that also originated from the underlying semiconductor (penetration depth $\sim 5 \mathrm{~nm}$ ). As the potential of the working electrode was varied, the core-level binding energy shifts were used to directly quantify the amount of band bending present in the semiconductor.

Both bare $\mathrm{ALD}-\mathrm{TiO}_{2}$ as well as $\mathrm{ALD}-\mathrm{TiO}_{2} / \mathrm{Ni}(2 \mathrm{~nm})$ electrodes were characterized with this experimental approach[57-59], using 1.0 M KOH(aq) as the electrolyte [57]. For bare ALD$\mathrm{TiO}_{2}$, the defect states caused Fermi level pinning as the applied potential was swept through the region that contained the defect states. However, the $\mathrm{ALD}-\mathrm{TiO}_{2} /$ solution system otherwise acted 
as a canonical semiconductor/liquid junction in which a space-charge (depletion) region developed in the semiconductor as the applied potential was shifted away from the flat-band potential (Fig. 4a and Fig. 5). Charge-carrier accumulation at the surface of the semiconductor was also observed when negative potentials were applied to the electrode. However, the addition of Ni changed the energetics of this system substantially. The solution (with the influence of the defect states) set the potentials of the $\mathrm{ALD}-\mathrm{TiO}_{2}$ band edges in the $\mathrm{ALD}-\mathrm{TiO}_{2} /$ solution system, but $\mathrm{Ni}$ pinned the band energies to the $\mathrm{Ni}$ layer and the $\mathrm{TiO}_{2}$ remained essentially under flat-band conditions throughout the entire applied potential range (Fig. 4b). Thus, the addition of $\mathrm{Ni}$ allowed for enhanced charge conduction at least partly by removing the rectifying space-charge region from the $\mathrm{TiO}_{2} /$ solution interface.
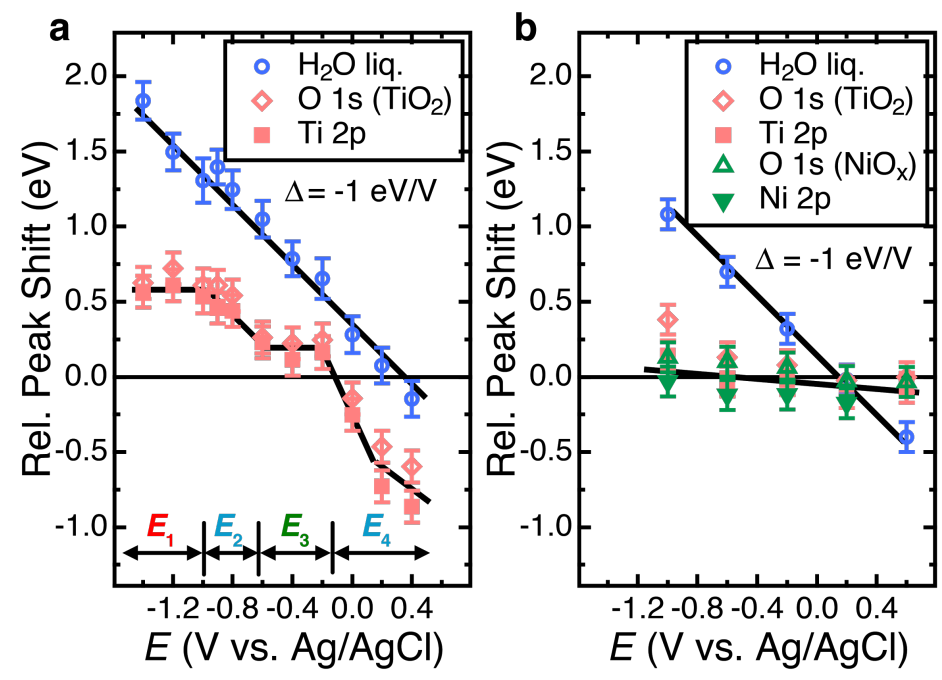

Figure 4. Peak shifts vs applied potential for (a) ALD-TiO $2 /$ solution and (b) ALD$\mathrm{TiO}_{2} / \mathrm{Ni} /$ solution interfaces. In both plots, a line indicating a binding energy shift of $1 \mathrm{eV} / \mathrm{V}$, which is expected for an ideal liquid and an ideal semiconductor under these conditions, is shown for the water $\mathrm{O}$ 1s peaks. For the titania (a) and nickel (b) data, a line of best fit is drawn as a guide to the eye. Data reproduced from reference [57]. 


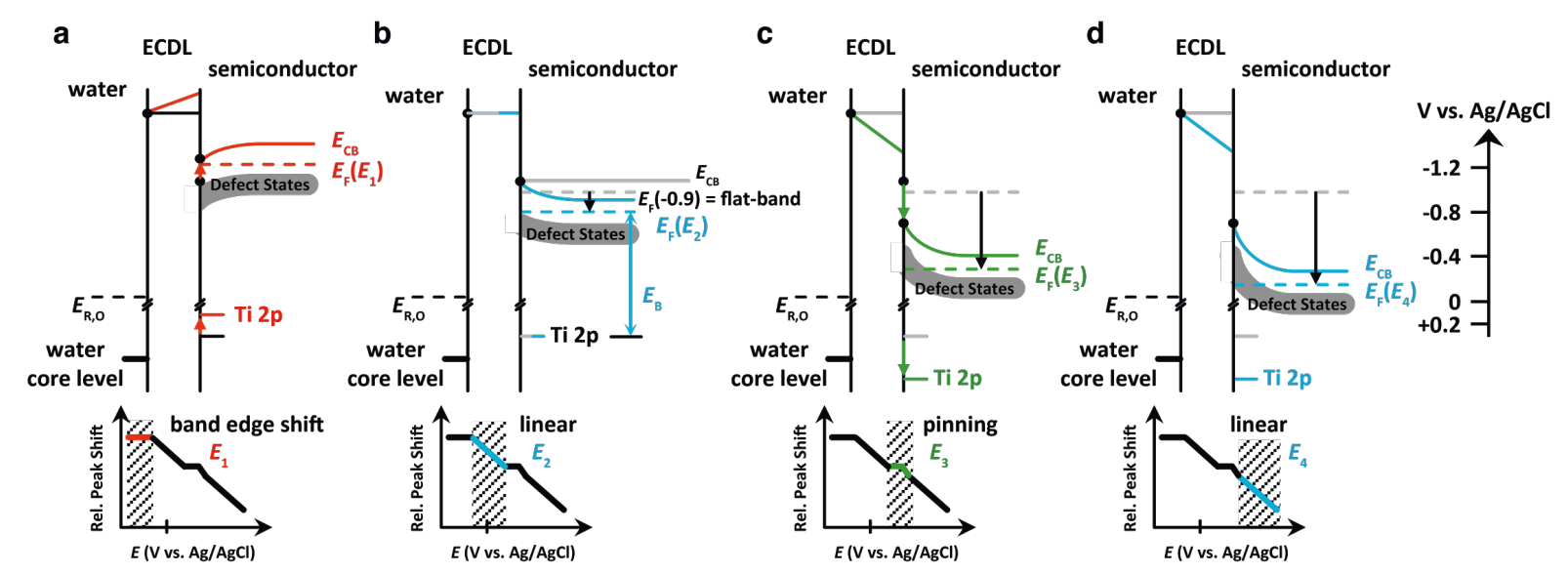

Figure 5. From the results in Figure 4a, four sections $\left(E_{1}-E_{4}\right)$ are deduced. Under very negative potentials, accumulation causes a shift in the band-edge positions. At more positive, and at very positive potentials ( $E_{2}$ and $\left.E_{4}\right)$, the band edges are fixed and potential is dropped in the space-charge region. In the region that contains defect states, $E_{3}$, the band edges shift due to charging or discharging of the defect states, causing Fermi level pinning. Any potential drop that does not occur in the semiconductor occurs in the electrochemical double layer (ECDL). Data reproduced from reference [57].

At least two charge conduction mechanisms are consistent with the behavior of these $\mathrm{TiO}_{2}$ films. The first possibility is that anodic current flow proceeds through defect states in the ALD- $-\mathrm{TiO}_{2}$, by a defect-state charge-hopping mechanism. This possibility is supported by the low value for the Richardson constant and by the ability of charge on the surface to easily oxidize water, which would be thermodynamically difficult for a conduction band-centered mechanism. The other primary mechanism that may explain the current flow is conduction-band centered. The use of $\mathrm{TiO}_{2}$ that has been prepared by a variety of means, including $\mathrm{TiO}_{2}$ that does not have a significant number of mid-gap defect states detectable by XPS, lends credence to this mechanism for at least some $\mathrm{TiO}_{2}$ materials. The operando XPS experiments do not necessarily favor one mechanism over the other, as the removal of the rectifying quality in the ALD- $\mathrm{TiO}_{2}$ 
could enhance current flow in either mechanism. Hence, elaboration of the precise nature of the conduction mechanism in such $\mathrm{TiO}_{2}$ films is a topic of continued interest[60].

\section{Nickel oxide}

\subsection{Background}

Transitional metal oxides that upon activation are intrinsically active for water oxidation have been previously used as protective layers on semiconductor photoanode surfaces. Kainthla et al. used a $\mathrm{Mn}_{2} \mathrm{O}_{3}$ coating on n-Si with a monolayer of $\mathrm{Pd}[61]$. This photoanode showed stable operation for $650 \mathrm{~h}$ at a current density of $1 \mathrm{~mA} \mathrm{~cm}^{-2}$. The ideal regenerative cell efficiency was not large, however, due to large catalytic overpotential losses as well as due to the low barrier height of the n-Si/ $\mathrm{Mn}_{2} \mathrm{O}_{3}$ interface. Recently, various transition metals or their oxides, including Mn[62], Fe[63], Ni[26, 64-70] and Ir[71], have been used to protect n-Si photoanodes for water oxidation in strongly alkaline or acidic electrolytes [72]. Protection of III-V and II-VI semiconductors in aqueous photoelectrochemical systems has also been studied. In this section, we review recent progress focused on the development of a nickel oxide based multifunctional coating that can protect unstable semiconducting photoanodes (including Si, II-VI and III-V group compound semiconductors) for solar-driven water oxidation. The deposition conditions required to obtain to the "SABOR" properties will be discussed. Additionally, the photoelectrochemical performance of $\mathrm{NiO}_{\mathrm{x}}$-protected photoanodes is described.

\subsection{Structural and morphological properties}

$\mathrm{NiO}_{\mathrm{x}}$ films have been synthesized using reactive RF sputtering directly on bare semiconductor surfaces. Thin films generally have a columnar structure, with a column/grain size that is sensitive to the deposition and substrate conditions. Figure 6a shows a typical 
morphology of a reactively sputtered $\mathrm{NiO}_{\mathrm{x}}$ thin film. All of the columns were aligned normal to the surface, with an equivalent grain size of $25 \mathrm{~nm}$ revealed by AFM and XRD analysis. Higher temperature synthesis generally resulted in films that had a higher crystallinity (Fig.6b) than films synthesized at lower deposition temperatures. At a fixed oxygen concentration, heating and substrate orientation had an insignificant effect on modification of the preferred grain orientation. $\mathrm{NiO}_{\mathrm{x}}$ films produced by reactive sputtering were fully oxidized and a metal phase was not detected in such materials (Fig. 6c).
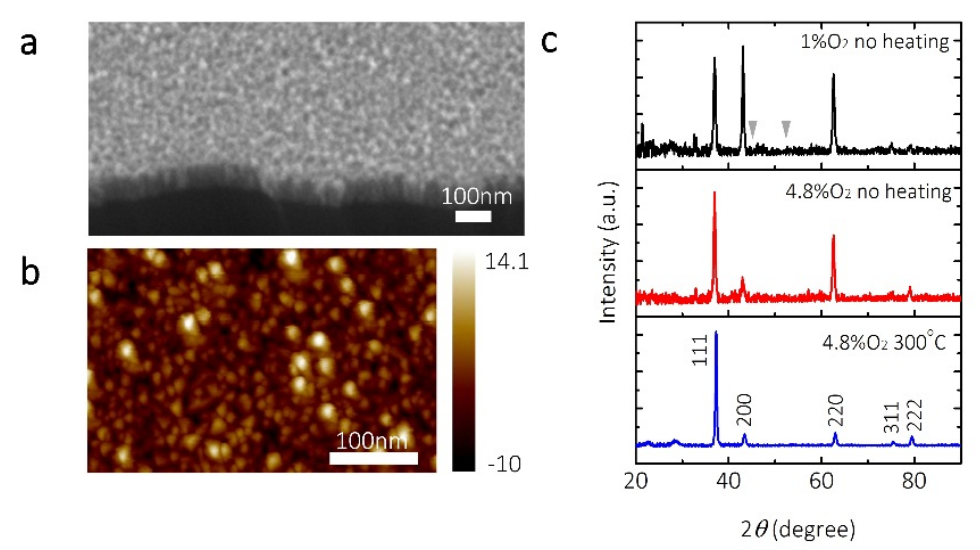

Figure 6. (a) Tilted cross-sectional SEM image and (b) AFM images of a typical $\mathrm{NiO}_{\mathrm{x}}$ film prepared on a planar Si substrate showing a columnar structure with an average column size of $25 \mathrm{~nm}$ in diameter. (c) XRD patterns of films produced under different atmospheric and temperature conditions, suggesting a polycrystalline nature of the film. Data reproduced from reference [67] and [73].

\subsection{Electrical conductivity}

The scattering of carriers at grain boundaries can be significant during in-plane conductivity measurements. Hence such measurements are not necessarily representative of the conduction along the column direction. Instead of traditional Hall measurements, the electrical 
conductivity and intrinsic dopant type/concentration were therefore measured using electrochemical methods, specifically by making contact with $\mathrm{Fe}(\mathrm{CN})_{6}{ }^{4-/ 3-}(\mathrm{aq})$, an electrochemically reversible, one-electron redox couple $\left[0.35 \mathrm{M} \mathrm{K}_{4} \mathrm{Fe}(\mathrm{CN})_{6} / 0.05 \mathrm{M} \mathrm{K}{ }_{3} \mathrm{Fe}(\mathrm{CN})_{6}\right.$ in $1.0 \mathrm{M} \mathrm{KCl}(\mathrm{aq})]$.

Such measurements indicated that increases in the oxygen concentration during reactive sputtering produced more resistive films. Films prepared using 4.8\% oxygen concentration showed a conductivity comparable to that of a metallic film (Fig. 7a) [67]. Because of its high conductivity along the column direction, increases in the $\mathrm{NiO}_{\mathrm{x}}$ thickness from 10 to $75 \mathrm{~nm}$ did not significantly alter the shape of the $J$-E data and did not produce significant increases in resistance of the photoanode. (Fig. 7b) [73]. Mott-Schottky measurements of the inverse of the differential capacitance vs applied potential showed that the films behaved as intrinsic p-type doped semiconductors with a carrier concentration of $\sim 10^{19} \mathrm{~cm}^{-3}[67]$. These observations were also supported by optical measurements, in which a large extinction coefficient was observed at long wavelengths, indicating a significant concentration of free carriers, as shown by the substantial carrier concentration indicated by the Mott-Schottky measurements. [73]. XPS analysis showed a correlation between the $\mathrm{Ni}(\mathrm{II}) / \mathrm{Ni}(\mathrm{III})$ ratio and the oxygen concentration during deposition [73]. 

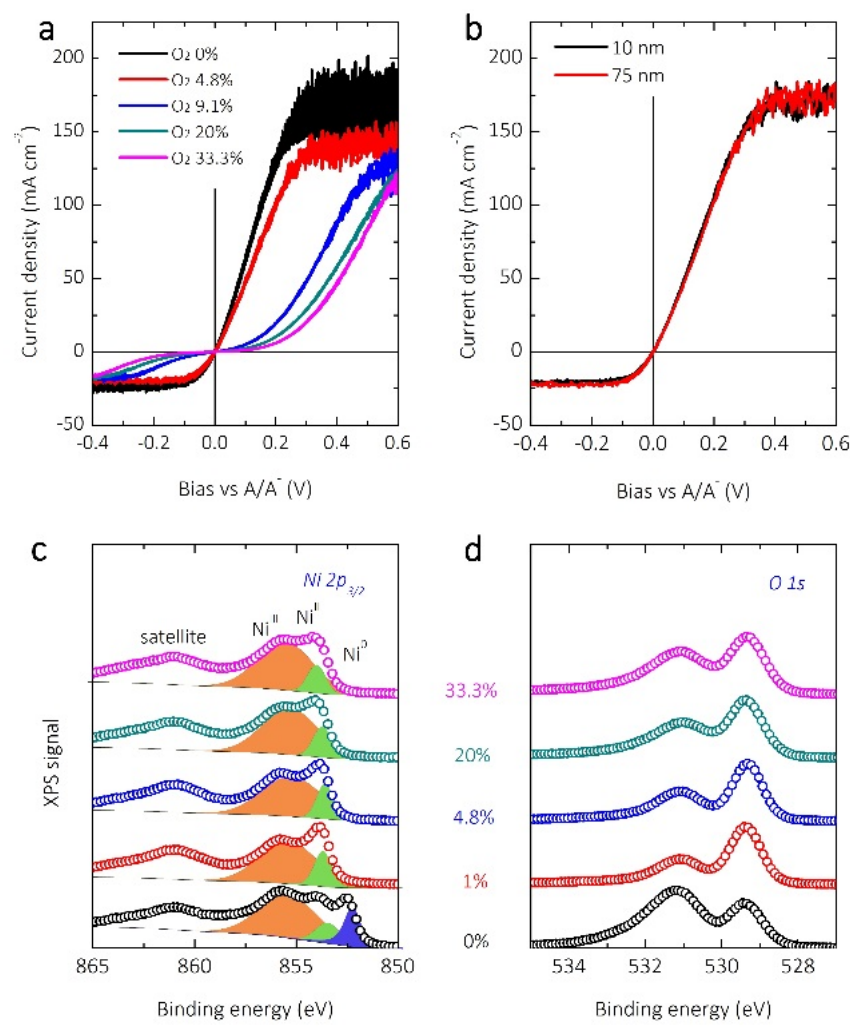

Figure 7. (a) $J$-E plots of $\mathrm{NiO}_{\mathrm{x}}$ films prepared under different oxygen concentrations on degenerately-doped $\mathrm{p}^{+}-\mathrm{Si}$ substrates, in contact with $\mathrm{Fe}(\mathrm{CN})_{6}{ }^{4-/ 3-}$ (aq). (b) $\mathrm{J}-\mathrm{E}$ plot of NiOx films coated $\mathrm{p}^{+}$-Si substrates with thicknesses of $10 \mathrm{~nm}$ and $75 \mathrm{~nm}$, prepared with a $4.8 \% \mathrm{O}_{2}$ atmosphere at $300^{\circ} \mathrm{C}$, in contact with $\mathrm{Fe}(\mathrm{CN})_{6}{ }^{4-3-}$ (aq). (c) and (d) XPS investigation of the Ni 2p and $\mathrm{O}$ 1s regions for films grown under various oxygen concentration.

\subsection{Optical properties}

Metallic electrocatalysts can absorb or reflect light; hence, optimization of the catalytic loading typically requires balancing the optical obscuration with the catalytic activity of the film. Generally, in the absence of surface texture, covalently bonded semiconductors whose refractive 
indices are 3-4 reflect a significant amount of light, based on the Fresnel equations. Such optical reflection losses can be smaller when water is the incident media instead of air, due to the higher refractive index of water than air[73]. However, the thickness of the water layer should be minimized due to its own absorption losses[69, 74]. The optical properties of the reactively sputtered $\mathrm{NiO}_{\mathrm{x}}$ film as well as of semiconductors coated by the $\mathrm{NiO}_{\mathrm{x}}$ film have been investigated using ultraviolet-visible spectroscopy, spectroscopic ellipsometry and in-situ transmission measurements. We first discuss $e x$-situ optical properties in air without contact with water or electrical bias, and then describe in-situ measurements of electrochromism under water oxidation conditions.

\subsubsection{Transparent antireflection coating}

$\mathrm{NiO}_{\mathrm{x}}$ films prepared by reactive sputtering are generally transparent. However, the degree of transparency is sensitive to the oxygen partial pressure, substrate temperature and deposition rate. Specifically, higher temperatures, higher oxygen partial pressures, and/or slower deposition rates led to films with high transparency. For example, Figure 8a shows optical images of $\mathrm{NiO}_{\mathrm{x}}$ films of various thicknesses that were prepared by reactive sputtering on quartz substrates. The films were highly transparent, showing a minimum absorption in the visible portion of the spectrum, and thus allowing for maximized absorption by the underlying semiconducting light absorber. The optical band gap of the $\mathrm{NiO}_{\mathrm{x}}$ film was measured to be $3.74 \mathrm{eV}$, as extracted from a Tauc plot based on the total transmittance measured by UV-Vis spectroscopy in conjunction with the extinction coefficient obtained using spectroscopic ellipsometry.

A crucial optical parameter for photovoltaics or photoelectrochemical cells is the index of refraction ( $n$-ik), because a strong reflection is expected at the interface, where a sharp transition 
of the refractive index is present. Refractive indices for most covalent semiconductors with bandgaps between 1 and $2 \mathrm{eV}$, such as Si, GaAs, InP, and CdTe, are typically 3-4 at $550 \mathrm{~nm}$, where the AM 1.5 solar flux is at its global maximum. When operating in water, at this wavelength an ideal single-layer quarter-wavelength antireflection coating should have a refractive index $\mathrm{n}_{\mathrm{AR}}=\sqrt{\left(\mathrm{n}_{\mathrm{water}} \cdot \mathrm{n}_{\mathrm{SC}}\right)}$ of 2-2.3, where $n_{\mathrm{AR}}, n_{\text {water }}$ and $n_{\mathrm{SC}}$ are the refractive indices of the antireflection coating, water and underlying semiconductor, respectively. The refractive index of the $\mathrm{NiO}_{\mathrm{x}}$ is $\sim 2.26$ at $550 \mathrm{~nm}$, which is nearly ideal for the aforementioned semiconductors[73]. Using the transfer matrix method, the total reflection spectra can be calculated based on the optical parameters of the film and the substrates. The calculated reflection spectra were in good agreement with the measured reflection spectra (Figure 8c and 8d). The optimized thickness for antireflection behavior is therefore $70-80 \mathrm{~nm}$, and varies only slightly with variation in either the underlying semiconductor materials or its morphology. The optimum thickness from the calculation also matched well with the experimental observations.

A single reflection minimum, typically set at the green wavelength, is achievable using a single-layer quarter-wavelength antireflection coating. However, this approach does not produce optimal absorption/antireflection behavior across the entire solar spectrum. To broaden the antireflection spectrum, a multi-layer or graded-index design is necessary. However, such an approach is more feasible for photovoltaic cells, in which both the chemical stability in strong acid/base and the electrical conductivity of the coating are secondary concerns. As part of the "SABOR” criteria, these two parameters are important to consider unless a strategy with a patterned catalyst design can be implemented, in which the conductivity requirements of the protection/antireflection coating can be relaxed[75]. Moreover, no universal antireflection material is available for different semiconductor light absorbers, due to their variation in 
refractive index. Additionally, for tandem designs, obtaining an optimal index of refraction and the optimal thickness of an antireflection coating when striving for the highest-possible current matching can be complicated by the properties of the photovoltaic components, including the quantum yield, morphology, and index of refraction.
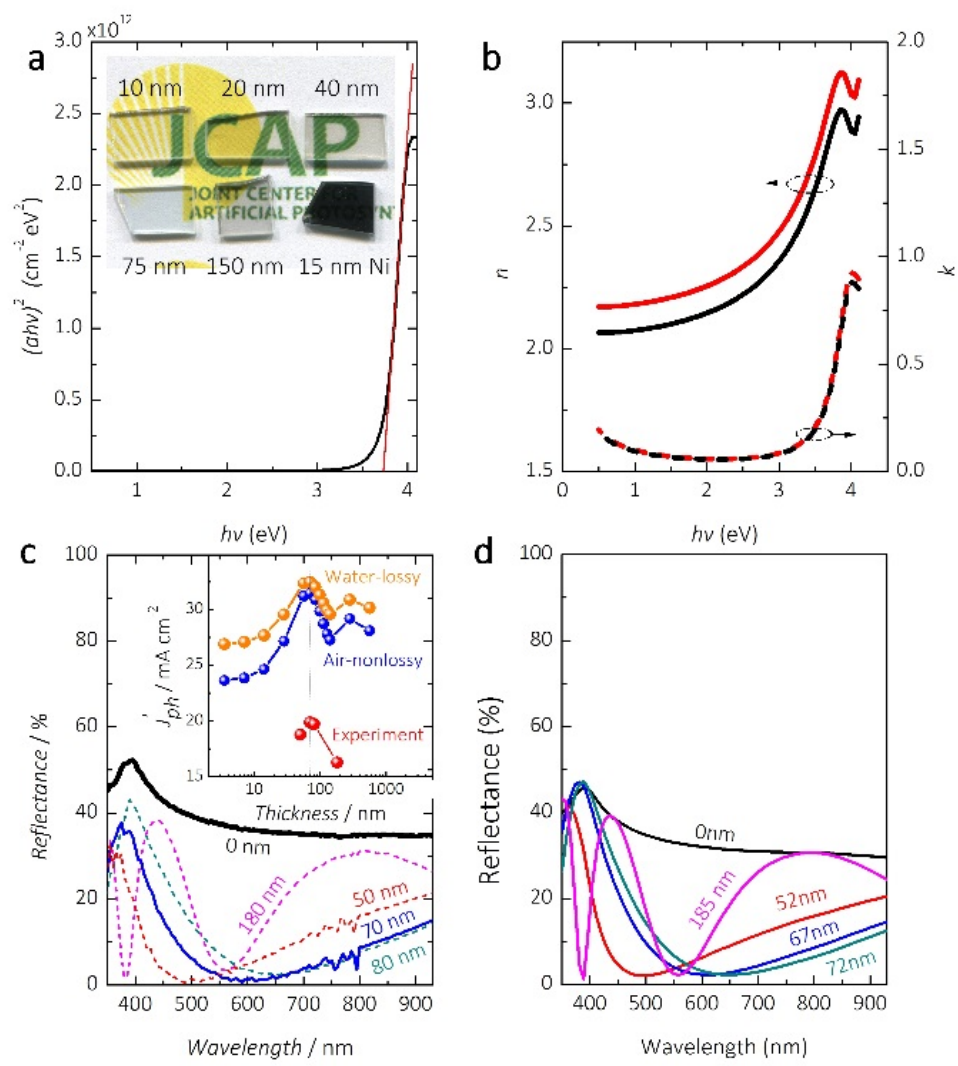

Figure 8. (a) Tauc plot of a $\mathrm{NiO}_{\mathrm{x}}$ film $(75 \mathrm{~nm})$ coated quartz substrate, showing a direct bandgap for the $\mathrm{NiO}_{\mathrm{x}}$ film of $3.74 \mathrm{eV}$. Inset shows an optical image of $\mathrm{NiO}_{\mathrm{x}}$ films on quartz substrates with various thicknesses; for comparison, a 15-nm nickel metal film is also shown. (b) $n$ and $k$ of a $\mathrm{NiO}_{\mathrm{x}}$ film measured on a $\mathrm{NiO}_{\mathrm{x}}$ coated planar $\mathrm{Si}$ substrate showing a position dependent indices caused by the columnar nature. (c) Measured total reflectance for $\mathrm{NiO}_{\mathrm{x}}$ coated crystalline InP substrate with various thicknesses of $\mathrm{NiO}_{\mathrm{x}}$. The inset shows calculated results assuming $100 \%$ internal quantum efficiency at energy above its band gap and experimental results for integrated 
photocurrent densities based on the reflectance spectra. (d) Calculated total reflectance for InP/NiO ${ }_{x}$ substrates with various $\mathrm{NiO}_{\mathrm{x}}$ thicknesses. Data is adopted from reference [73] and [69].

\subsubsection{Electrochromism}

Electrochromism is a change in optical absorption in response to charging or discharging the electrochemical cell as a function of a change in the applied potential. The oxides of $\mathrm{W}, \mathrm{Ti}$, $\mathrm{V}, \mathrm{Nb}$ and Mo exhibit cathodic electrochromism, while oxides of $\mathrm{Cr}, \mathrm{Mn}, \mathrm{Co}, \mathrm{Fe}, \mathrm{Ni}$ and Ir exhibit anodic electrochromism. The electrochromism of $\mathrm{NiO}_{\mathrm{x}}$ in alkaline electrolytes originates from the increased concentration of $\mathrm{Ni}^{3+}$ in the form of $\mathrm{NiOOH}$ or even $\mathrm{Ni}_{2} \mathrm{O}_{3}$ on the surface. These species, which are the intermediate products during the water oxidation reaction on $\mathrm{Ni}$ based catalysts, have higher absorption coefficients and smaller bandgaps than the $\mathrm{NiO}_{\mathrm{x}}$ itself, and thus are the cause of such coloration. Previous work in this field by Trotochaud, Boettcher and coworkers has demonstrated that ultrathin catalyst layers are often necessary optimal to minimize absorptive losses in the catalyst, especially due to electrochromism. [76] Alternatively $\mathrm{NiFeO}_{\mathrm{x}}$ has low optical absorption, which makes it an excellent catalytic material for use in such devices [77].

To effectively suppress electrochromism such that minimum optical obscuration can be obtained under water oxidation conditions, the deposition conditions need to be optimized to reduce the active surface area and thus to reduce the concentration of $\mathrm{Ni}(\mathrm{III})$ in the film under working conditions. However, a reduction in the active surface area typically results in a reduction in the overall electrocatalytic activity of the film. A reduction in active surface area may also affect the electrical conductivity of the film. Reactively sputtered $\mathrm{NiO}_{\mathrm{x}}$ films typically showed activation processes during the first 10 cyclic voltammetric (CV) cycles in $1.0 \mathrm{M}$ 
$\mathrm{KOH}(\mathrm{aq})$ electrolyte, and this activation can be assigned to an increased active surface area and/or to intercalation of Fe from impurities in solution. This activation typically resulted in a stabilization of the electrochromism in the film.

Figure 9 shows the dynamic transmittance responses of two samples prepared on glass that had been coated with a transparent conducting oxide (FTO glass), as a function of applied potential (0.93-1.93 V vs. RHE) in a three-electrode configuration at a fixed incident wavelength (550 nm). Samples prepared at $300{ }^{\circ} \mathrm{C}$ under a deposition rate of $0.2 \AA \mathrm{s}^{-1}$ (purple), or without substrate heating at a deposition rate of $0.6 \AA \mathrm{s}^{-1}$ (orange), showed different levels of anodic coloration. $\mathrm{NiO}_{\mathrm{x}}$ films that were deposited using a slower deposition rate and/or higher temperatures exhibited a suppression of the self-shadowing process and yielded columnar structures with large grain sizes and high grain densities. Dense films that had large grains and few grain boundaries contained less electrochemically active surface area and thus were less susceptible to electrochromic darkening, which minimizes the optical losses during operation and provides a stable transmitted spectrum for the underlying semiconductors[69]. 


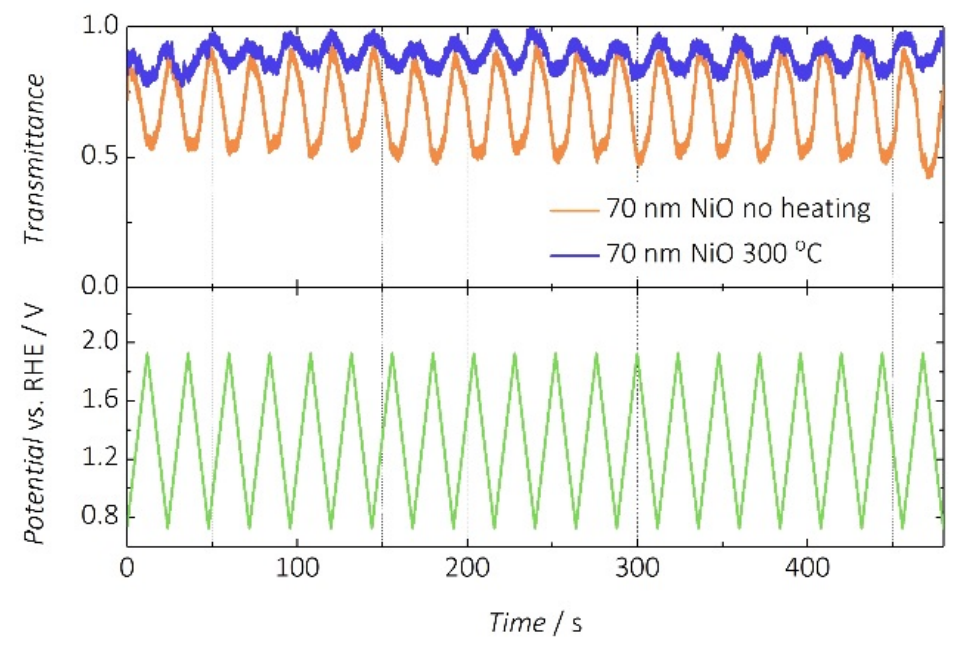

Figure 9. Comparison of electrochromism on $\mathrm{NiO}_{\mathrm{x}}$ coated FTO substrates deposited at different temperatures and deposition rate, at a fixed incident wavelength of $550 \mathrm{~nm}$. Data is adopted from reference [69].

\subsection{Catalytic activity and stability}

The catalytic activity of reactively sputtered $\mathrm{NiO}_{\mathrm{x}}$ generally improved and stabilized after $10 \mathrm{CV}$ cycles in $1.0 \mathrm{M} \mathrm{KOH}(\mathrm{aq})$ between $0.93 \mathrm{~V}$ and $1.93 \mathrm{~V}$ vs. the reversible hydrogen electrode (RHE).[67] In this process, the redox peak areas increased and the activity improved. This behavior could be caused by thickening of the $\mathrm{Ni}(\mathrm{OH})_{2} / \mathrm{NiOOH}$ layer or by incorporation of impurity ions, especially Fe, in the activated catalyst phase[73]. Similar to electrical conductivity and electrochromism, the catalytic activity is also sensitive to the deposition conditions[73]. Figure 10a shows the effect of oxygen concentration on the observed catalytic activity of such films. The activity of $\mathrm{NiO}_{\mathrm{x}}$ films prepared with an oxygen concentration of $4.8 \%$ or lower was similar to that observed for the hydroxide/oxyhydroxide derived from the oxidation of Ni metal, giving an overpotential of $\sim 330 \mathrm{mV}$ to produce an anodic current density of $10 \mathrm{~mA}$ 
$\mathrm{cm}^{-2}$ for water oxidation. The activity decreased with increasing oxygen concentration during film deposition. Variation in the deposition temperature had no significant effect on the catalytic activity of the film, although higher deposition temperatures suppressed the electrochromism.

The catalytic activity, and the capability of the film to protect the underlying $\mathrm{Si}$, was independent of the thickness of the $\mathrm{NiO}_{\mathrm{x}} \cdot \mathrm{p}^{+}-\mathrm{Si} / \mathrm{NiO}_{\mathrm{x}}$ dark electrodes showed a sustained activity for $100 \mathrm{~h}$ at a constant current density of $30 \mathrm{~mA} \mathrm{~cm}{ }^{-2}$. The redox peak was also maintained without a significant increase in area (Figure 10b), which is proportional to the optical obscuration.
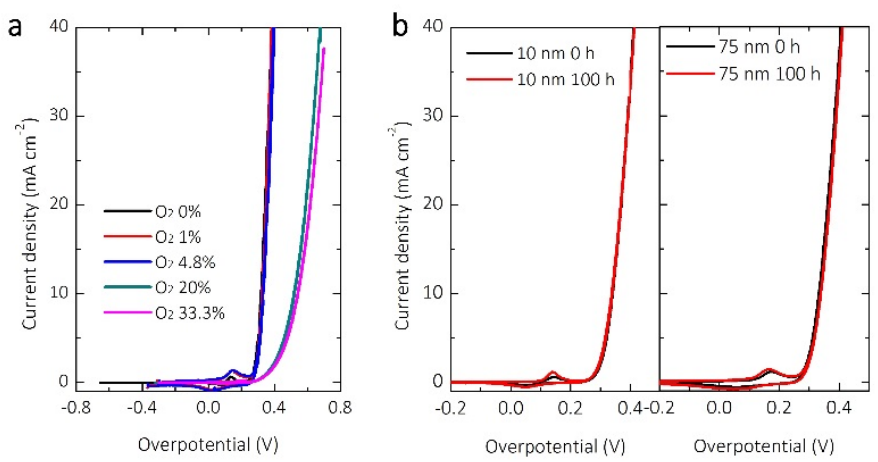

Figure 10. (a) $J-E$ curves for $\mathrm{NiO}_{\mathrm{x}}$ coated degenerately doped $\mathrm{p}^{+}$-Si dark electrode prepared with different concentrations of $\mathrm{O}_{2}$. (b) $J$-E curves before and after 100 hours operation at a constant current density of $30 \mathrm{~mA} \mathrm{~cm}^{-2}$. Data reproduced from reference [73].

\subsection{Heterogeneous modification of interfacial energetics}

Due to Fermi-level pinning by surface states, the barrier heights of $\mathrm{NiO}_{\mathrm{x}}$ coated covalent semiconductors were typically low. Therefore, photovoltages and the solar-to- $\mathrm{O}_{2}$ ideal 
regenerative cell conversion efficiencies remained low without using a buried homogeneous junction[67, 69]. Homogeneous junctions are typically constructed through high-profile techniques such as ion-implantation, molecular beam epitaxy, or diffusion at high temperature. Moreover, many semiconductors cannot be doped to form high-quality homogeneous junctions. For example, dopants in small grain-size polycrystalline films often migrate along grain boundaries, which produces majority-carrier shunts and degrades the performance of photovoltaic cells. Therefore, it is desirable to develop materials and techniques to tune the interfacial energetics to obtain suppressed dark currents and thus to improve the photovoltages at low temperature and low cost. We recently found [78] that a dual layer structure ( $\sim 2 \mathrm{~nm} \mathrm{SiO}_{\mathrm{x}}$ from hot acid treatment $+\sim 2 \mathrm{~nm} \mathrm{CoO}$ from low temperature ALD) produced a strong field passivation on n-Si (100) surfaces. The equivalent open-circuit voltage obtained on n$\mathrm{Si} / \mathrm{SiO}_{\mathrm{x}} / \mathrm{CoO}_{\mathrm{x}} / \mathrm{NiO}_{\mathrm{x}}$ interfaces under illumination by a simulated AM $1.5 \mathrm{G}$ spectrum with an intensity of $100 \mathrm{~mW} \mathrm{~cm}^{-2}$ was $\sim 570 \mathrm{mV}$, and the solar-to- $\mathrm{O}_{2}$ ideal regenerative cell conversion efficiency was $2.1 \%$, comparable to that of a protected $\mathrm{np}^{+}-\mathrm{Si}$ using an identical $\mathrm{NiO}_{\mathrm{x}}$ film (Figure 11a). Specifically, the $\mathrm{n}-\mathrm{Si} / \mathrm{SiO}_{\mathrm{x}, \mathrm{RCA}} / \mathrm{CoO}_{\mathrm{x}} / \mathrm{NiO}_{\mathrm{x}}$ photoanode showed a photocurrentonset potential of $\sim-240 \mathrm{mV}$ relative to the formal potential for water oxidation $\left(E^{o^{\prime}}\left(\mathrm{O}_{2} / \mathrm{H}_{2} \mathrm{O}\right)=\right.$ 1.23 V vs RHE, at $\mathrm{pH}=14$ ), solar-to $\mathrm{O}_{2}(\mathrm{~g})$ ideal regenerative-cell conversion efficiency of $\sim 2.1 \%$ and a stability of $1700 \mathrm{~h}$ continuous solar water oxidation for $>1700 \mathrm{~h}$ in $1.0 \mathrm{M} \mathrm{KOH}(\mathrm{aq})$ under $100 \mathrm{~mW} \mathrm{~cm}^{-2}$ of simulated solar illumination[78]. X-ray photoelectron spectroscopy (XPS) confirmed the presence of the $\mathrm{CoO}_{\mathrm{x}}$ layer (Figure 11b and 11c) while atomic force microscopy (AFM) clearly showed the morphology change of n-Si/SiO ${ }_{x, R C A}$ after deposition of $\mathrm{CoO}_{\mathrm{x}}$ and $\mathrm{NiO}_{\mathrm{x}}$ (Figure 11e and 11f). 

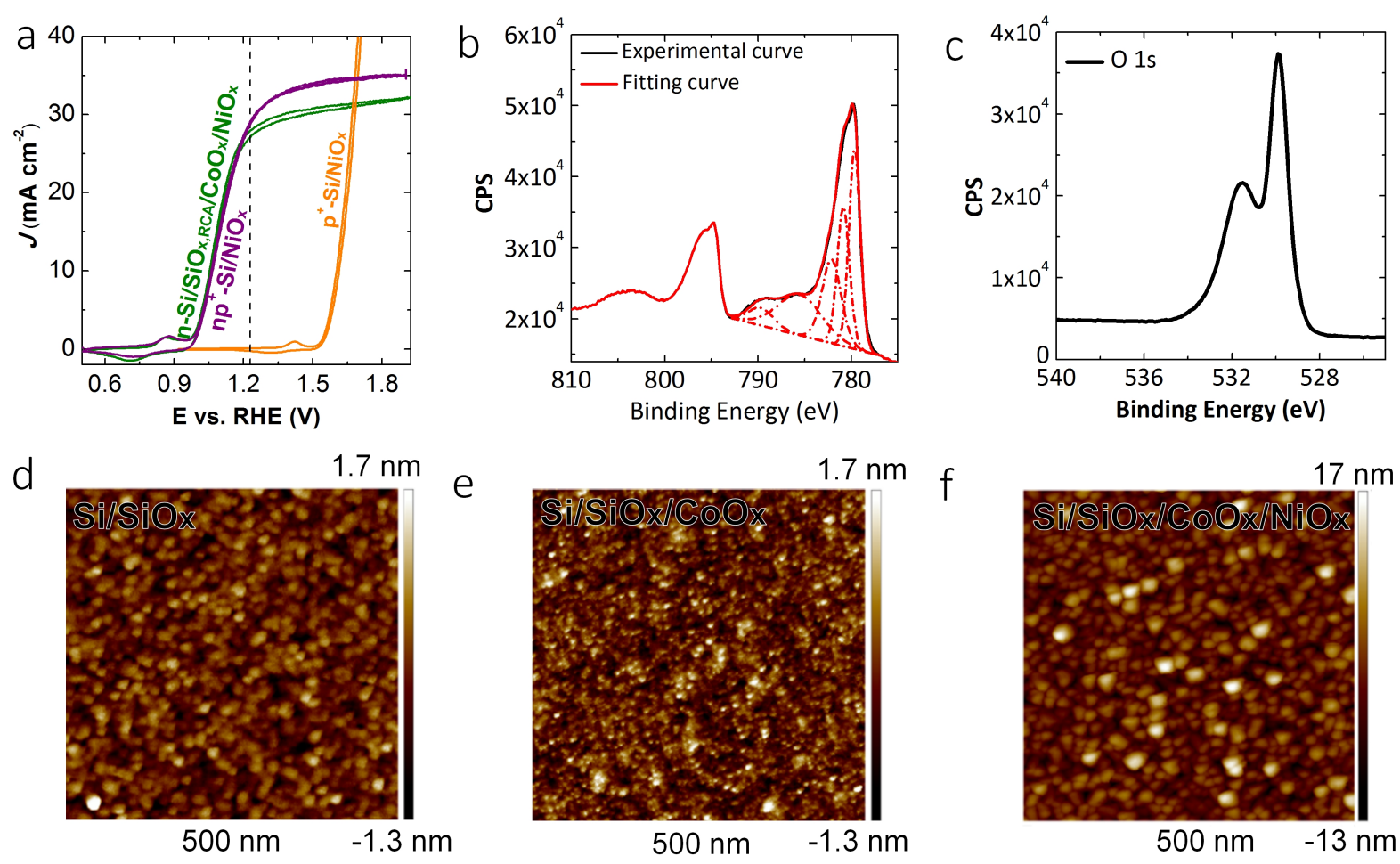

Figure 11. (A) Representative current-density versus potential (J-E) behavior of n$\mathrm{Si} / \mathrm{SiOx}, \mathrm{RCA} / \mathrm{CoO}$ x/NiOx and n-Si/SiOx,RCA/NiOx photoanodes in contact with 1.0 M KOH (aq) in the dark and under $100 \mathrm{~mW}$ cm-2 of simulated AM1.5G solar illumination. The J-E behavior of a non-photoactive $\mathrm{p}^{+-\mathrm{Si}} \mathrm{NiOx}$ electrode is also shown. The dark dashed line indicates the formal potential for water oxidation, Eo'(O2/H2O). (B, C) X-Ray photoelectron spectra (XPS) for an n-Si/SiOx,RCA/CoOx photoelectrode. The binding energies used for fitting of the Co 2p3/2 peaks were $779.6 \mathrm{eV}, 780.8 \mathrm{eV}, 782.2 \mathrm{eV}, 785.5 \mathrm{eV}, 789.7 \mathrm{eV}$. (D, E, F) AFM images showing the surface morphology of n-Si/SiOx,RCA, n-Si/SiOx,RCA/CoOx, and n$\mathrm{Si} / \mathrm{SiOx}, \mathrm{RCA} / \mathrm{CoOx} / \mathrm{NiOx}$, respectively. Data reproduced from reference [78].

\subsection{Stabilization of self-passivating semiconductors}


The reactively sputtered $\mathrm{NiO}_{\mathrm{x}}$ films have been shown to allow for operational stability of various semiconductors for thousands of hours under oxidizing conditions, passing an amount of charge equivalent to that passed in $>1$ year of outdoor operation under unconcentrated illumination. Table 1 summarizes the performance and stability of a variety of $\mathrm{NiO}_{\mathrm{x}}$-coated inorganic semiconducting photoanodes.

Table 1. Performance and stability of $\mathrm{NiO}_{\mathrm{x}}$ coated photoanodes

\begin{tabular}{|c|c|c|c|c|}
\hline Structure & Condition & $E_{\text {onset }}(\mathrm{mV})$ & $\eta(\%)$ & $t$ (h) \\
\hline np $-\mathrm{Si} / \mathrm{NiO}_{\mathrm{x}}$ & 1.0M KOH, AM $1.5100 \mathrm{~mW} \mathrm{~cm}{ }^{-2}$ & -180 & 2.1 & 1200 \\
\hline $\mathrm{a}-\mathrm{Si}: \mathrm{H} / \mathrm{NiO}_{\mathrm{x}}$ & 1.0M KOH, AM $1.5100 \mathrm{~mW} \mathrm{~cm}{ }^{-2}$ & -116 & 0.11 & 100 \\
\hline $\mathrm{HTJ}-\mathrm{Si} / \mathrm{NiO}_{\mathrm{x}}$ & 1.0M KOH, AM $1.5100 \mathrm{~mW} \mathrm{~cm}{ }^{-2}$ & -280 & 1.45 & 200 \\
\hline $\mathrm{CdTe} / \mathrm{NiO}_{\mathrm{x}}$ & 1.0M KOH, AM $1.5100 \mathrm{~mW} \mathrm{~cm}{ }^{-2}$ & -70 & 0.08 & 1000 \\
\hline $\mathrm{np}^{+}-\mathrm{InP} / \mathrm{NiO}_{\mathrm{x}}$ & 1.0M KOH, AM $1.5100 \mathrm{~mW} \mathrm{~cm}^{-2}$ & -370 & 2.1 & 48 \\
\hline$n p-\mathrm{InP} / \mathrm{NiO}_{\mathrm{x}}$ & 1.0 M K-Bi, AM $1.5100 \mathrm{~mW} \mathrm{~cm}^{-2}$ & -250 & 1.0 & 600 \\
\hline $\mathrm{n}-\mathrm{Si} / \mathrm{CoO}_{\mathrm{x}} / \mathrm{NiO}_{\mathrm{x}}$ & 1.0M KOH, AM $1.5100 \mathrm{~mW} \mathrm{~cm}^{-2}$ & -270 & 2.2 & 1700 \\
\hline
\end{tabular}

${ }^{*} E_{\text {onset }}$ is the photocurrent onset voltage vs. the equilibrium potential for water oxidation $(1.23 \mathrm{~V}$

vs. RHE), $\eta$ is the ideal solar-to-oxygen regenerative cell conversion efficiency, and $t$ is the length of demonstrated photoelectrochemical stability under a constant bias.

\subsection{Summary}

The combination of optical transparency, electrical conductivity, chemical stability, corrosion protection, antireflectivity and catalytic activity enables the use of $\mathrm{NiO}_{\mathrm{x}}$ for the stabilization of unstable semiconductors (such as amorphous Si, amorphous Si passivated crystalline $\mathrm{Si}, \mathrm{CoO}_{\mathrm{x}}$ passivated crystalline $\mathrm{Si}$, crystalline $\mathrm{CdTe}$ and $\mathrm{InP}$ ) for solar-driven water 
oxidation in strongly alkaline solutions, as well as in near-neutral $\mathrm{pH}$ buffered solutions that might be relevant to $\mathrm{CO}_{2}$ reduction.

In contrast to protective films formed by $\mathrm{ALD}-\mathrm{TiO}_{2}$, where the defects result primarily from atmospheric conditions as well as atomic vacancies, the defective nature in the reactively sputtered $\mathrm{NiO}_{\mathrm{x}}$ films results primarily from the columnar structure as well as from pinholes caused by the arcs during plasma sputtering. The sputtered $\mathrm{NiO}_{\mathrm{x}}$ films are therefore better suited to protect semiconductors that passivate as opposed to semiconductors that actively dissolve under photoanodic operating conditions [79]. Anodic protection is a very effective method to protect metals or alloys (such as stainless steel) from acid (sulfuric acid), by shifting the potential of the substrate into the passive region of the anodic polarization curve. Similarly, Si etching stops when a potential positive of the passivation potential is applied. This process is independent of the dopant type or surface crystalline orientation[80], and thus is different from the etching of Si in alkaline electrolytes[81]. Anodic passivation is also used in microelectromechanical systems (MEMS) to effectively control the Si etching stop in alkaline solution, thereby enabling the definition of micromachined membranes and cantilevers. Typically, a stoichiometric oxide with a transition layer is formed at the Si surface, and the oxide thickness depends on the passivation conditions (concentration, temperature, and bias) and substrate doping (type and concentration) [82]. However, even at potentials that are positive with respect to the open-circuit potential but that are negative of the passivation potential, Si corrosion can be significant, as evidenced by the generation of $\mathrm{H}_{2}$ gas under such conditions [83]. Therefore, we must be cautious in comparing stability metrics between studies, as the method of determining "stability" can be highly study-dependent. 


\section{Conclusions}

Both titania and $\mathrm{NiO}_{\mathrm{x}}$ protection layers can provide $>100$ h of stability to silicon and other semiconductors in relatively harsh oxidizing operating conditions. These conditions allow for efficient solar-driven water splitting or fuel-forming devices to be constructed under conditions that allow for intrinsically safe operation. The $\mathrm{ALD}-\mathrm{TiO}_{2}$ approach allows for the protection of otherwise unstable semiconductors, including those that may not be stable by selfpassivation. Sputtered $\mathrm{NiO}_{\mathrm{x}}$ films provide excellent stability, catalytic, and optical characteristics, particularly on semiconductors that have a self-passivating mechanism under anodic bias. Further work is ongoing to expand the working space for these approaches to larger potential ranges, other environments, and new deposition methods. Furthermore, the use of these protection layers is being explored to form high efficiency, fully integrated, intrinsically safe solar fuels generation systems.

\section{Acknowledgements}

This work was supported through the Office of Science of the U.S. Department of Energy (DOE) under award no. DE-SC0004993 to the Joint Center for Artificial Photosynthesis, a DOE Energy Innovation Hub, as well as by the Moore Foundation. The Advanced Light Source is supported by the Director, Office of Science, Office of Basic Energy Sciences, of the U.S. Department of Energy under Contract no. DE-AC02- 05CH11231. The authors thank Van Seebass for assistance in the preparation of this manuscript. 


\section{References:}

[1] M.G. Walter, E.L. Warren, J.R. McKone, S.W. Boettcher, Q. Mi, E.A. Santori and N.S. Lewis, Chemical Reviews, 110 (2010) 6446.

[2] N.S. Lewis, The ELectrochemical Society's Interface, 22 (2013) 43.

[3] J.D. Benck, T.R. Hellstern, J. Kibsgaard, P. Chakthranont and T.F. Jaramillo, ACS Catalysis, 4 (2014) 3957.

[4] F. Safizadeh, E. Ghali and G. Houlachi, International Journal of Hydrogen Energy, 40 (2015) 256.

[5] A.I. Carim, F.H. Saadi, M.P. Soriaga and N.S. Lewis, Journal of Materials Chemistry A, 2 (2014) 13835.

[6] J. Qiao, Y. Liu, F. Hong and J. Zhang, Chemical Society Reviews, 43 (2014) 631.

[7] A. Fujishima and K. Honda, Nature, 238 (1972) 37.

[8] J.A. Seabold and K.-S. Choi, Journal of the American Chemical Society, 134 (2012) 2186.

[9] J.A. Switzer, J. Electrochem. Soc., 133 (1986) 722.

[10] S.K. Pilli, T.G. Deutsch, T.E. Furtak, L.D. Brown, J.A. Turner and A.M. Herring, Physical Chemistry Chemical Physics, 15 (2013) 3273.

[11] M.F. Lichterman, M.R. Shaner, S.G. Handler, B.S. Brunschwig, H.B. Gray, N.S. Lewis and J.M. Spurgeon, The Journal of Physical Chemistry Letters, 4 (2013) 4188.

[12] C. Ding, J. Shi, D. Wang, Z. Wang, N. Wang, G. Liu, F. Xiong and C. Li, Physical Chemistry Chemical Physics, 15 (2013) 4589.

[13] F.F. Abdi, N. Firet and R. van de Krol, ChemCatChem, 5 (2013) 490.

[14] F.F. Abdi, L. Han, A.H.M. Smets, M. Zeman, B. Dam and R. van de Krol, Nat Commun, 4 (2013).

[15] G. Hodes, L. Thompson, J. DuBow and K. Rajeshwar, J. Am. Chem. Soc., 105 (1983) 324.

[16] S. Hu, C. Xiang, S. Haussener, A.D. Berger and N.S. Lewis, Energy \& Environmental Science, 6 (2013) 2984.

[17] S. Haussener, C. Xiang, J.M. Spurgeon, S. Ardo, N.S. Lewis and A.Z. Weber, Energy \& Environmental Science, 5 (2012) 9922.

[18] J.R. Bolton, S.J. Strickler and J.S. Connolly, Nature, 316 (1985) 495.

[19] O. Khaselev and J.A. Turner, Science, 280 (1998) 425.

[20] E.L. Miller, R.E. Rocheleau and X.M. Deng, International Journal of Hydrogen Energy, 28 (2003)

615.

[21] D.V. Esposito, I. Levin, T.P. Moffat and A.A. Talin, Nat Mater, 12 (2013) 562.

[22] S. Hu, M.R. Shaner, J.A. Beardslee, M.F. Lichterman, B.S. Brunschwig and N.S. Lewis, Science, 344 (2014) 1005.

[23] M. Pourbaix, Atlas of electrochemical equilibria in aqueous solutions, Pergamon Press, Oxford; New York, 1966.

[24] Y. Nakato, T. Ohnishi and H. Tsubomura, Chemistry Letters, 4 (1975) 883.

[25] R.C. Kainthla, B. Zelenay and J.O.M. Bockris, Journal of The Electrochemical Society, 134 (1987)

841.

[26] M.J. Kenney, M. Gong, Y. Li, J.Z. Wu, J. Feng, M. Lanza and H. Dai, Science, 342 (2013) 836.

[27] Y.W. Chen, J.D. Prange, S. Dühnen, Y. Park, M. Gunji, C.E.D. Chidsey and P.C. McIntyre, Nat Mater, 10 (2011) 539.

[28] F.R.F. Fan, B.L. Wheeler, A.J. Bard and R.N. Noufi, Journal of The Electrochemical Society, 128 (1981) 2042.

[29] M.S. Wrighton, P.T. Wolczanski and A.B. Ellis, Journal of Solid State Chemistry, 22 (1977) 17.

[30] S.Y. Reece, J.A. Hamel, K. Sung, T.D. Jarvi, A.J. Esswein, J.J.H. Pijpers and D.G. Nocera, Science, 334 (2011) 645. 
[31] Y. Nakato, Y. Egi, M. Hiramoto and H. Tsubomura, J. Phys. Chem., 88 (1984) 4218.

[32] H. Morisaki, T. Watanabe, M. Iwase and K. Yazawa, Appl. Phys. Lett., 29 (1976) 338.

[33] K. Rajeshwar, N.R. de Tacconi and C.R. Chenthamarakshan, Chemistry of Materials, 13 (2001)

2765.

[34] F.R.F. Fan, G.A. Hope and A.J. Bard, J. Electrochem. Soc., 129 (1982) 1647.

[35] J.D. Luttmer, D. Konrad and I. Trachtenberg, J. Electrochem. Soc., 132 (1985) 1054.

[36] E.L. Warren, J.R. McKone, H.A. Atwater, H.B. Gray and N.S. Lewis, Energy Environ. Sci., 5 (2012)

9653.

[37] Y.J. Hwang, A. Boukai and P. Yang, Nano Lett., 9 (2009) 410.

[38] M. Moriya, T. Minegishi, H. Kumagai, M. Katayama, J. Kubota and K. Domen, J. Am. Chem. Soc., 135 (2013) 3733.

[39] A.C. Nielander, M.R. Shaner, K.M. Papadantonakis, S.A. Francis and N.S. Lewis, Energy \& Environmental Science, 8 (2015) 16.

[40] J.W. Ager lii, M. Shaner, K. Walczak, I.D. Sharp and S. Ardo, Energy \& Environmental Science, (2015).

[41] S. Hu, N.S. Lewis, J.W. Ager, J. Yang, J.R. McKone and N.C. Strandwitz, Journal of Physical Chemistry C, (Submitted).

[42] B. Mei, B. Seger, T. Pedersen, M. Malizia, O. Hansen, I. Chorkendorff and P.C.K. Vesborg, J. Phys. Chem. Lett., 5 (2014) 1948.

[43] G.H. Lin, M. Kapur, R.C. Kainthla and J.O.M. Bockris, Applied Physics Letters, 55 (1989) 386.

[44] Y. Yamada, N. Matsuki, T. Ohmori, H. Mametsuka, M. Kondo, A. Matsuda and E. Suzuki, International Journal of Hydrogen Energy, 28 (2003) 1167.

[45] C.C.L. McCrory, S. Jung, J.C. Peters and T.F. Jaramillo, J. Am. Chem. Soc., 135 (2013) 16977.

[46] N. Kelly and T. Gibson, Int. J. Hydrogen Energy, 31 (2006) 1658.

[47] J.J.H. Pijpers, M.T. Winkler, Y. Surendranath, T. Buonassisi and D.G. Nocera, P. N. A. S., 108 (2011) 10056.

[48] J. Jin, K. Walczak, M.R. Singh, C. Karp, N.S. Lewis and C. Xiang, Energy \& Environmental Science, 7 (2014) 3371.

[49] M.R. Singh, K. Papadantonakis, C. Xiang and N.S. Lewis, Energy \& Environmental Science, (2015).

[50] W.J. Youngblood, S.-H.A. Lee, Y. Kobayashi, E.A. Hernandez-Pagan, P.G. Hoertz, T.A. Moore, A.L. Moore, D. Gust and T.E. Mallouk, Journal of the American Chemical Society, 131 (2009) 926.

[51] B. O'Regan and M. Gratzel, Nature, 353 (1991) 737.

[52] S.A. Campbell, H.S. Kim, D.C. Gilmer, B. He, T. Ma and W.L. Gladfelter, IBM Journal of Research and Development, 43 (1999) 383.

[53] M.F. Lichterman, A.I. Carim, M.T. McDowell, S. Hu, H.B. Gray, B.S. Brunschwig and N.S. Lewis, Energy \& Environmental Science, 7 (2014) 3334.

[54] M.T. McDowell, M.F. Lichterman, A.I. Carim, R. Liu, S. Hu, B.S. Brunschwig and N.S. Lewis, ACS Applied Materials \& Interfaces, (2015).

[55] M.R. Shaner, S. Hu, K. Sun and N.S. Lewis, Energy \& Environmental Science, 8 (2015) 203.

[56] S.M. Sze and K.K. Ng, Physics of semiconductor devices, Wiley-Interscience, Hoboken, N.J., 2007.

[57] M.F. Lichterman, S. Hu, M.H. Richter, E.J. Crumlin, S. Axnanda, M. Favaro, W. Drisdell, Z. Hussain, T. Mayer, B.S. Brunschwig, N.S. Lewis, Z. Liu and H.-J. Lewerenz, Energy \& Environmental Science, (2015).

[58] M.F. Lichterman, M.H. Richter, S. Hu, E.J. Crumlin, S. Axnanda, M. Favaro, W. Drisdell, Z. Hussain, T. Mayer, B. Brunschwig, N.S. Lewis, H.J. Lewerenz and Z. Liu, ECS Transactions, 66 (2015) 97.

[59] M.H. Richter, M.F. Lichterman, S. Hu, E.J. Crumlin, T. Mayer, S. Axnanda, M. Favaro, W. Drisdell, Z. Hussain, B. Brunschwig, N.S. Lewis, Z. Liu and H.J. Lewerenz, ECS Transactions, 66 (2015) 105. 
[60] B. Mei, T. Pedersen, P. Malacrida, D. Bae, R. Frydendal, O. Hansen, P.C.K. Vesborg, B. Seger and I. Chorkendorff, The Journal of Physical Chemistry C, (2015).

[61] R.C. Kainthla, B. Zelenay and J.O.M. Bockris, J. Electrochem. Soc., 133 (1986) 248.

[62] N.C. Strandwitz, D.J. Comstock, R.L. Grimm, A.C. Nichols-Nielander, J. Elam and N.S. Lewis, J. Phys. Chem. C, 117 (2013) 4931.

[63] K. Jun, Y.S. Lee, T. Buonassisi and J.M. Jacobson, Angew. Chem. Int. Ed., 51 (2012) 423.

[64] K. Sun, N. Park, Z. Sun, J. Zhou, J. Wang, X. Pang, S. Shen, S.Y. Noh, Y. Jing, S. Jin, P.K.L. Yu and D. Wang, Energy \& Environmental Science, 5 (2012) 7872.

[65] B. Mei, A.A. Permyakova, R. Frydendal, D. Bae, T. Pedersen, P. Malacrida, O. Hansen, I.E.L. Stephens, P.C.K. Vesborg, B. Seger and I. Chorkendorff, J. Phys. Chem. Lett., 5 (2014) 3456.

[66] W. Cui, Z. Xia, S. Wu, F. Chen, Y. Li and B. Sun, ACS Appl. Mater. Interfaces, (2015).

[67] K. Sun, M.T. McDowell, A.C. Nielander, S. Hu, M.R. Shaner, F. Yang, B.S. Brunschwig and N.S. Lewis, J. Phys. Chem. Lett., 6 (2015) 592.

[68] K. Sun, X. Pang, S. Shen, X. Qian, J.S. Cheung and D. Wang, Nano Lett., 5 (2013) 2064.

[69] K. Sun, Y. Kuang, E. Verlage, B.S. Brunschwig, C.W. Tu and N.S. Lewis, Adv. Energy Mater., (2015)

n/a.

[70] G. Li and S. Wang, J. Electroanal. Chem. Interfac. Electrochem., 227 (1987) 213.

[71] B. Mei, B. Seger, T. Pedersen, M. Malizia, O. Hansen, I. Chorkendorff and P.C.K. Vesborg, J. Phys. Chem. Lett., 5 (2014) 1948.

[72] K. Sun, S. Shen, Y. Liang, P.E. Burrows, S.S. Mao and D. Wang, Chem. Rev., 114 (2014) 8662.

[73] K. Sun, F.H. Saadi, M.F. Lichterman, W.G. Hale, H.-P. Wang, X. Zhou, N.T. Plymale, S.T.

Omelchenko, J.-H. He, K.M. Papadantonakis, B.S. Brunschwig and N.S. Lewis, Proc. Natl. Acad. Sci. USA, (2015).

[74] H. Doscher, J.F. Geisz, T.G. Deutsch and J.A. Turner, Energy Environ. Sci., 7 (2014) 2951.

[75] Y. Chen, K. Sun, H. Audesirk, C. Xiang and N. Lewis, Energy Environ. Sci., (2015).

[76] L. Trotochaud, T.J. Mills and S.W. Boettcher, J. Phys. Chem. Lett., 4 (2013) 931.

[77] L. Trotochaud, S.L. Young, J.K. Ranney and S.W. Boettcher, J. Am. Chem. Soc., 136 (2014) 6744.

[78] X. Zhou, R. Liu, K. Sun, D. Friedrich, M.T. McDowell, F. Yang, S.T. Omelchenko, F.H. Saadi, A.C.

Nielander, S. Yalamanchili, K.M. Papadantonakis, B.S. Brunschwig and N.S. Lewis, Energy Environ. Sci., (2015).

[79] M.J. Madou, K.W. Frese and S.R. Morrison, J. Phys. Chem., 84 (1980) 3423.

[80] O.J. Glembocki, R.E. Stahlbush and M. Tomkiewicz, J. Electrochem. Soc., 132 (1985) 145.

[81] E.D. Palik, J.W. Faust, H.F. Gray and R.F. Greene, J. Electrochem. Soc., 129 (1982) 2051.

[82] J.M. Lopez-Villegas, M. Navarro, S. Marco, J. Samitier, J.R. Morante, A. Gotz and J. Esteve, J. Electrochem. Soc., 151 (2004) H227.

[83] E.D. Palik, O.J. Glembocki and I. Heard, J. Electrochem. Soc., 134 (1987) 404. 


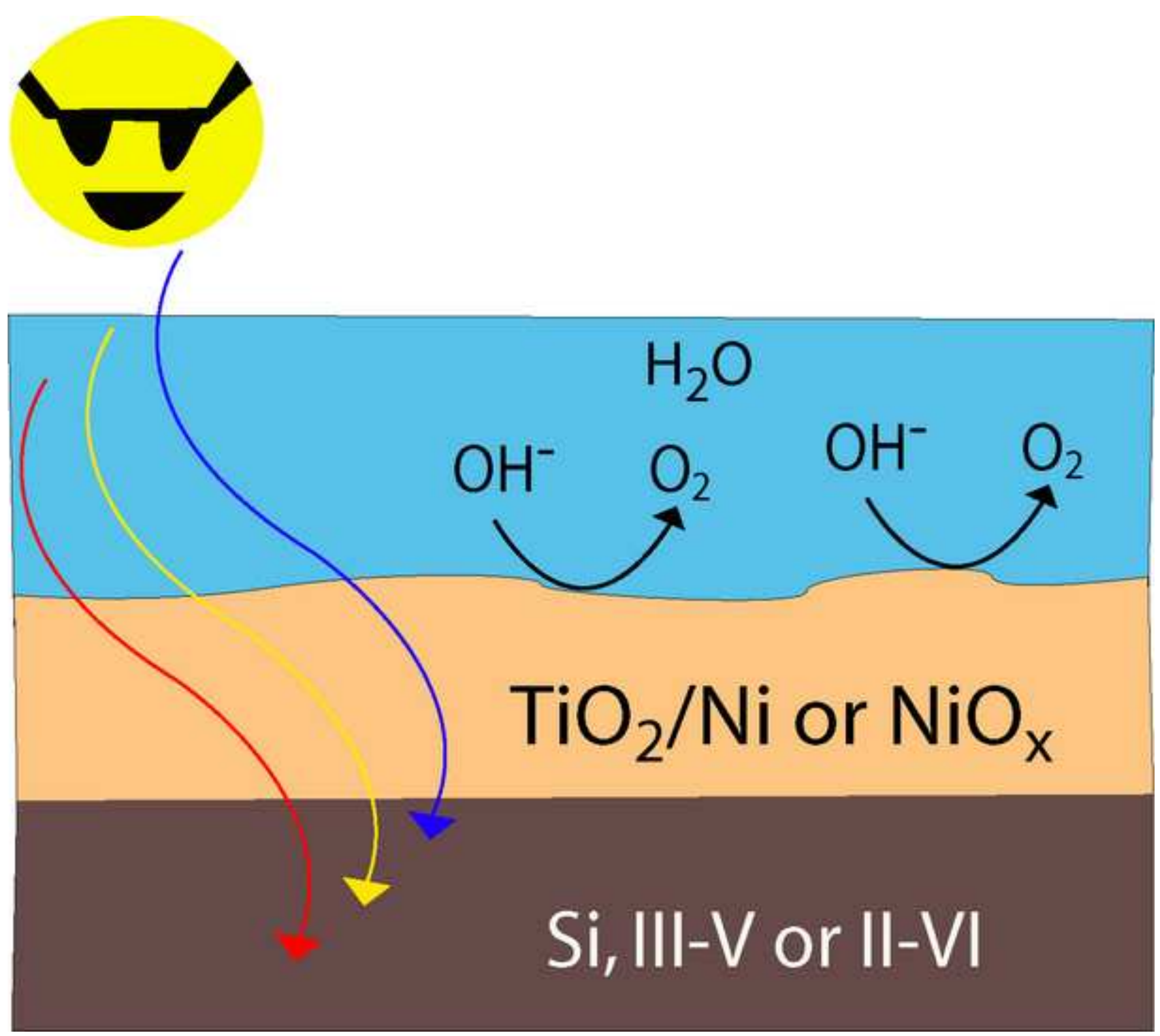

